\title{
The Cerebellar Interpositus Nucleus and the Dynamic Control of Learned Motor Responses
}

\author{
Raudel Sánchez-Campusano, ${ }^{1,2}$ Agnès Gruart, ${ }^{1}$ and José M. Delgado-García ${ }^{1}$ \\ ${ }^{1}$ División de Neurociencias, Universidad Pablo de Olavide, Sevilla 41013, Spain, and ²Centro de Biofísica Médica, Universidad de Oriente, Santiago de Cuba \\ 90500, Cuba
}

The role played by the cerebellum in movement control requires knowledge of interdependent relationships between kinetic neural commands and the performance (kinematics) of learned motor responses. The eyelid motor system is an excellent model for studying how simple motor responses are elaborated and performed. Kinetic variables $(n=24)$ were determined here by recording the firing activities of orbicularis oculi motoneurons and cerebellar interpositus neurons in alert cats during classical conditioning, using a delay paradigm. Kinematic variables $(n=36)$ were selected from eyelid position, velocity, and acceleration traces recorded during the conditioned stimulus - unconditioned stimulus interval. Optimized experimental and analytical tools allowed us to determine the evolution of kinetic and kinematic variables, the dynamic correlation functions relating motoneuron and interpositus neuron firing to eyelid conditioning responses, the falling correlation property of the interpositus nucleus across the successive training sessions, the time and significance of the linear relationships between these variables, and finally, the phase-inversion property of interpositus neurons with respect to acquired conditioned responses. Whereas motoneurons encoded eyelid kinematics at every instant of the dynamic correlation range and generated the natural oscillatory properties of the neuromuscular elements involved in eyeblinks, interpositus neurons did not directly encode eyelid performance: namely, their contribution was only slightly significant in the dynamic correlation range, and this regularity caused the integrated neuronal activity to oscillate by progressively inverting phase information. Therefore, interpositus neurons seem to play a modulating role in the dynamic control of learned motor responses, i.e., they could be considered a neuronal phase-modulating device.

Key words: interpositus nucleus; facial motoneuron; cats; cerebellum; classical conditioning; learning; motor control

\section{Introduction}

The enigmatic role of cerebellar circuits in relation to the generation and control of spontaneous and acquired motor responses has been variously ascribed to a putative center for motor coordination and integration (Eccles et al., 1967; Thach et al., 1992), a neural center controlling motor timing of the different muscles involved in a given movement (Llinás and Welsh, 1993; Welsh and Llinás, 1997; Lang et al., 1999; Kitazawa and Wolpert, 2005), the place for motor learning and memory storage (Ito, 1984; Krupa et al., 1993; Mauk, 1997; Bracha et al., 2001; Christian and Thompson, 2003) and, in a more parsimonious way, that of a center designed for the reinforcement and/or proper performance of ongoing movements (Holmes, 1939; Welsh and Harvey, 1991; Llinás and Welsh, 1993; Gruart et al., 2000; DelgadoGarcía and Gruart, 2002; Seidler et al., 2002; Jiménez-Díaz et al., 2004). Nevertheless, for a proper understanding of cerebellar

Received Feb. 4, 2007; revised April 25, 2007; accepted April 26, 2007.

This work was supported by Ministerio de Ciencia y Tecnología Grant BFU2005-01024 and Junta de Andalucía Grant CVI-122. We thank Drs. Liset Menéndez de la Prida and Adonis Moschovakis for their comments and suggestions on a previous version of this manuscript. We thank Yulaima Favier and Roger Churchill for their editorial help and Sergio Rodriguez for his help in the preparation of the color figures.

Correspondence should be addressed to Prof. José M. Delgado-García, División de Neurociencias, Universidad Pablo de Olavide, Carretera de Utrera, Km. 1, Sevilla 41013, Spain. E-mail: jmdelgar@upo.es.

DOI:10.1523/JNEUROSCI.0488-07.2007

Copyright $\odot 2007$ Society for Neuroscience $\quad$ 0270-6474/07/276620-13\$15.00/0 functioning, it will be necessary to approach the neural activity of cerebellar circuits during the actual performance of spontaneous, reflex, and learned movements. Moreover, cerebellar unitary activity should be correlated with both the activity present in the final common pathway (i.e., that of the motoneurons participating in the generation of the selected motor responses) and the kinematics (position, velocity, and acceleration) of the motor system involved.

In this regard, the eyelid motor system appears a suitable model for the study of cerebellar function in the acquisition of new motor abilities, because the brainstem and cerebellar circuits involved have been described precisely (Krupa et al., 1993; Llinás and Welsh, 1993; Mauk, 1997; Bracha et al., 2001; Carey and Lisberger, 2002; Delgado-García and Gruart, 2002; Morcuende et al., 2002; Christian and Thompson, 2003), the inputs and outputs of the system can be presented and/or measured quantitatively (Evinger et al., 1991; Gruart et al., 1995), and the neuronal activity of the relevant centers can be recorded in vivo during the actual performance of associative learning tasks (Trigo et al., 1999; Gruart et al., 2000; Chen and Evinger, 2006). Moreover, this motor system can be easily trained using classical conditioning paradigms (Gormezano et al., 1983). Nevertheless, the kinetic (neurally generated) motor commands and the kinematic (i.e., physical mechanics of the eyelid, including muscle activity) characterization of learned motor responses requires exhaustive 
A

\section{DIAGRAMMATIC REPRESENTATION OF THE EXPERIMENTAL DESIGN}

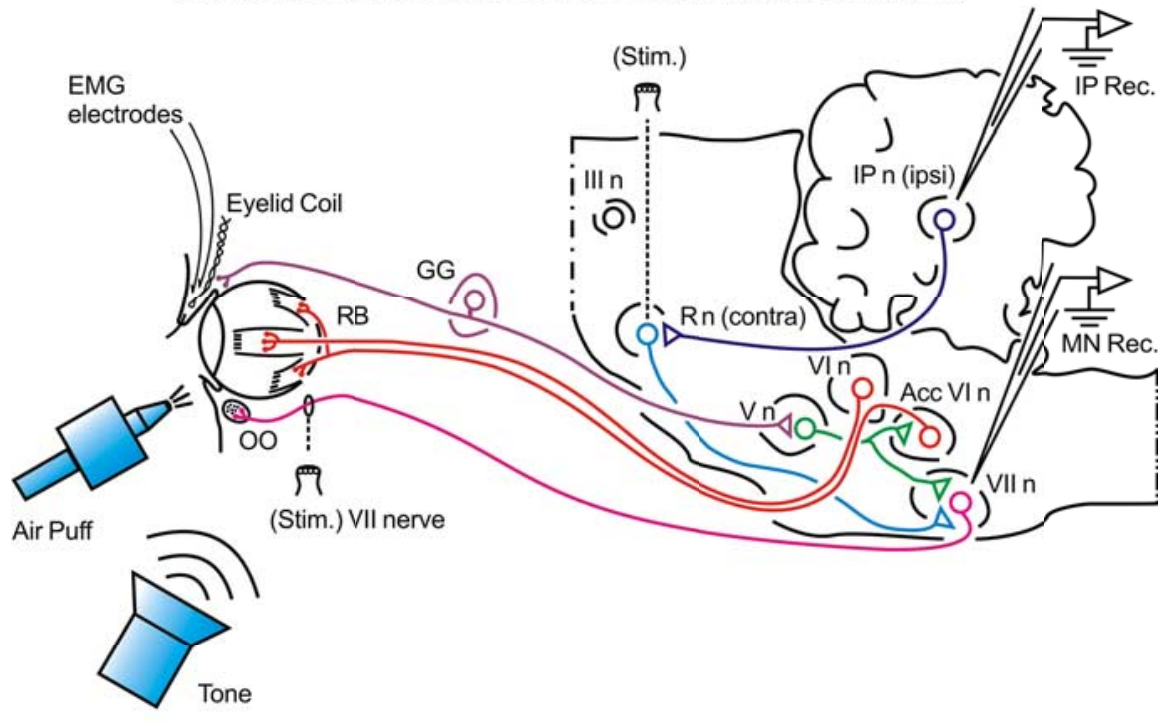

B

DELAY CONDITIONING PARADIGM

$\mathrm{cs}$ Tone $(370 \mathrm{~ms}, 600 \mathrm{~Hz}, 90 \mathrm{~dB})$

US

Air puff $\left(100 \mathrm{~ms}, 3 \mathrm{~kg} / \mathrm{cm}^{2}\right)$

Figure 1. Diagrammatic representation of the experimental design. $A$, The characterization of kinetic neural commands and of eyelid kinematics requires a precise measurement of exhaustive correlation indicators. The kinetic variables were determined here from the firing properties of antidromically identified orbicularis oculi $(00)$ motoneurons located in the facial nucleus $(\mathrm{VII} n)$ and interpositus neurons located in the cerebellar posterior interpositus nucleus (IP n). In turn, the kinematic variables were collected from eyelid position, velocity, and acceleration data. A complete list of kinetic and kinematic parameters measured in this study is included in Tables 1 and 2 . The two types of variable were associated by means of dynamic correlation analysis. The diagram also illustrates the stimulating (Stim.) and recording (Rec.) sites, as well as the eyelid coil and EMG electrodes implanted in the upper eyelid. III n, Oculomotor complex; V n, trigeminal nucleus; VI, abducens nucleus; AccVI n, accessory abducens nucleus; GG, Gasser ganglion; $\mathrm{Rn}$, red nucleus. $\boldsymbol{B}$, For classical conditioning of eyelid responses, we used a delay paradigm consisting of a tone $(370 \mathrm{~ms}$, $600 \mathrm{~Hz}, 90 \mathrm{~dB})$ as a $\left(S\right.$. The $\left(S\right.$ started $270 \mathrm{~ms}$ before and coterminated with an air puff $\left(100 \mathrm{~ms}, 3 \mathrm{~kg} / \mathrm{cm}^{2}\right)$ used as an US.

knowledge of interdependent relationships between physiological variables. For this, powerful analytical tools (such as cluster analysis, multiparametric evolution of involved variables, dynamic correlation functions, and oscillatory properties) need to be used to achieve a proper understanding of cerebellar functioning in the behaving animal during the very process of motor and/or associative learning (Belsley et al., 1980; Allen and Cady, 1982; Hair et al., 1998; Grafen and Hails, 2002).

In the present study, kinetic variables involved in the generation of eyelid conditioned responses (CRs) were determined by recording the firing activities of identified orbicularis oculi motoneurons (i.e., the final common pathway) and cerebellar interpositus neurons (the area under study) in alert behaving cats during classical conditioning, using a delay paradigm. For this, a tone was presented for $370 \mathrm{~ms}$ as a conditioned stimulus (CS), followed $270 \mathrm{~ms}$ from its start by an air puff $(100 \mathrm{~ms})$ directed at the left cornea as an unconditioned stimulus (US). The kinematic variables were collected from eyelid position, velocity, and acceleration traces recorded during the CS-US interval using the search-coil technique (Gruart et al., 1995), as well as from the electromyographic (EMG) activity of the orbicularis oculi muscle. The two types of variable were associated by means of multivariate cluster analysis and dynamic correlation analysis (Belsley et al., 1980; Allen and Cady, 1982; Banfield and Raftery, 1993;
Hair et al., 1998). Results allow us to propose that orbicularis oculi motoneurons certainly encode eyelid kinematics directly at every instant of the dynamic correlation range, as well as generate the natural oscillatory properties of the neuromuscular elements involved in eyelid kinematics. In contrast, interpositus neurons do not directly encode eyelid kinematics but do play a modulating role in the dynamic control of learned motor responses, i.e., they could be considered a neuronal phase-modulating device.

\section{Materials and Methods}

Subjects. Experiments were performed on seven adult cats (weighing 2.1-2.8 kg on arrival) obtained from an authorized supplier (IffaCredo, Arbresle, France). All experiments were performed in accordance with guidelines of the European Union (86/609/EU) for the use of laboratory animals in chronic experiments and were approved by the Institution Committee for animal care and handling.

Surgical procedures. Animals were anesthetized with sodium pentobarbital $(35 \mathrm{mg} / \mathrm{kg}$, i.p.) after a protective injection of atropine sulfate $(0.5 \mathrm{mg} / \mathrm{kg}$, i.m. $)$. As illustrated in Figure $1 A$, animals were implanted with a search coil (five turns, $3 \mathrm{~mm}$ in diameter) in the center of the left upper eyelid, at $2 \mathrm{~mm}$ from the lid margin. The coil was made from Teflon-coated multistranded stainless steel wire, with an external diameter of $50 \mu \mathrm{m}$. Animals were also implanted with two hook electrodes, bared 1 $\mathrm{mm}$ at their tips, in the ipsilateral orbicularis oculi muscle, for EMG recordings. Recording electrodes were made of the same wire. Four of the animals were prepared for the chronic recording of antidromically identified posterior interpositus neurons. For this, a stimulating bipolar (200 $\mu \mathrm{m}$ enamel-coated silver wire) electrode was implanted in the magnocellular division of the contralateral (right) red nucleus following stereotaxic coordinates (Berman, 1968). For comparative purposes, three animals were prepared for the chronic recording of facial motoneurons projecting to the orbicularis oculi muscle. For this, a pair of stainless steel hook electrodes was aimed at the zygomatic subdivision of the facial nerve, $1-2 \mathrm{~mm}$ posterior to the external canthus. For each animal, a recording window $(5 \times 5 \mathrm{~mm})$ was opened in the occipital bone to allow access to the ipsilateral (left) interpositus nucleus or facial nucleus. The dura mater was removed, and an acrylic chamber was constructed around the opening. The cerebellar surface was protected with a piece of silicone sheet and sterile gauze and hermetically closed using a plastic cover. At the end of the implantation procedure, a head-holding system was attached to the skull in stereotaxic coordinates. Wires were soldered to a socket fixed to the holding system. A more detailed description of these chronic preparations have been published previously (Trigo et al., 1999; Gruart et al., 2000; Jiménez-Díaz et al., 2004).

Recordings and stimulating techniques. Eyelid movements were recorded with the magnetic search-coil technique (Gruart et al., 1995). The EMG activity of the orbicularis oculi muscle was recorded with differential amplifiers at a bandwidth of $0.1 \mathrm{~Hz}$ to $10 \mathrm{kHz}$. Neural activity in both facial and interpositus nuclei was recorded with glass micropipettes filled with $2 \mathrm{M} \mathrm{NaCl}$ (3-6 $\mathrm{M} \Omega$ of resistance) and with the help of an NEX-1 preamplifier (Biomedical Engineering, Thornwood, NY). For antidromic activation of selected neurons, we used single- or double- (inter- 
val of 1-2 ms) cathodal square pulses (50 $\mu$ s) with current intensities $<300 \mu \mathrm{A}$. Only antidromically identified interpositus neurons $(n=174)$ and orbicularis oculi motoneurons $(n=110)$ were stored and analyzed. Site location and identification procedures have been described in detail for both interpositus neurons (Gruart et al., 2000) and facial motoneurons (Trigo et al., 1999). Tones were applied from a loudspeaker located $80 \mathrm{~cm}$ below the animal's head. Air puffs were applied through the opening of a plastic pipette ( $3 \mathrm{~mm}$ in diameter) located $2 \mathrm{~cm}$ from the left eye.

Classical conditioning. Classical conditioning of eyelid responses was achieved by the use of a delay conditioning paradigm (Fig. $1 B$ ). For this, a tone $(370 \mathrm{~ms}, 600 \mathrm{~Hz}, 90 \mathrm{~dB})$ was used as CS. The tone was followed 270 $\mathrm{ms}$ from its onset by an air puff $\left(100 \mathrm{~ms}, 3 \mathrm{~kg} / \mathrm{cm}^{2}\right)$ directed at the left cornea as a US. Thus, the tone and the air puff terminated simultaneously. The experimental subjects underwent a sequence of two habituation, 10 conditioning sessions, and three extinction sessions. In all cases, the conditioning session consisted of 12 blocks separated by a variable $(5 \pm 1 \mathrm{~min})$ interval. Each block consisted of 10 trials separated by intervals of $30 \pm 10 \mathrm{~s}$. The CS was presented alone in the first trial of each block. A complete conditioning session lasted for $\sim 2 \mathrm{~h}$. The CS was presented alone during habituation and extinction sessions for the same number of blocks per session and trials per block and with similar random interblock and intertrial distribution (Gruart et al., 1995).

Histology. At the end of the recording sessions, animals were deeply reanesthetized $(50 \mathrm{mg} / \mathrm{kg}$ sodium pentobarbital, i.p.). Electrolytic marks were placed in selected recording sites with a tungsten electrode $(1 \mathrm{~mA}$ for $30 \mathrm{~s}$ ). Animals were perfused transcardially with saline and phosphate-buffered Formalin. Serial sections $(50 \mu \mathrm{m})$ including the cerebellum and the brainstem were mounted on glass slides and stained with toluidine blue for confirmation of the recording sites.

Physiological parameter definitions. A total of 60 parameters were determined in an automated way, taking into account physiological criteria based on a kinetic-kinematic characterization of the neuronal firing activities and the learned motor responses. For a quantitative determination of kinetic neural commands, a total of 24 kinetic parameters (Table 1) were quantified from the selected interpositus neurons and orbicularis oculi motoneurons. According to the performance of learned motor responses, 36 kinematic parameters (Table 2) were quantified from the selected eyelid position, velocity, and acceleration traces.

Data collection and analysis. Eyelid position, EMG and neuronal activity, and rectangular pulses corresponding to CS and US presentations were stored digitally on a computer, using an analog-to-digital converter (CED 1401 Plus; Ceta Electronic Design, Cambridge, UK). Commercial computer programs (Spike 2 and SIGAVG; Ceta Electronic Design) were used for acquisition and on-line conventional analysis. The off-line analysis and quantification and representation programs used here were developed by one of the authors (R.S.-C.) with the help of Matlab routines (MathWorks, Natick, MA).

On the basis of direct records of neuronal activity from the cerebellar interpositus nucleus or the facial nucleus, the action potential pulses were quantified. In all cases, the quantification algorithm took into account the identification of the standard waveform of the action potential and the absolute refractory period (i.e., the mean duration of the action potential) and relative refractory period (minimum interspike time interval). The instantaneous firing rate was calculated as the inverse of the interspike intervals. Velocity and acceleration profiles were computed digitally as the first and second derivatives of eyelid position records after low-pass filtering of the data $(-3 \mathrm{~dB}$ cutoff at $50 \mathrm{~Hz}$ and zero gain at is $\approx 100 \mathrm{~Hz}$ ). The power spectra were calculated using the fast Fourier transform, and the significance of power spectral peaks was tested with the $\chi^{2}$-distributed test for spectral density functions.

Computed results were processed for statistical analysis using the Statistics Matlab Toolbox. Collected data were analyzed using a multivariate cluster technique. As statistical inference procedures, both ANOVA (estimate of variance both within groups and between groups, on the basis of one dependent measure) and multivariate ANOVA (MANOVA) (estimate of variance in multiple dependent parameters across groups) were used to assess the statistical significance of differences between groups. The corresponding statistical significance test (i.e., $F_{[(m-1),(m-1) \times(n-1),(1-m)]}$ statistic) was

\section{Table 1. The 24 kinetic variables selected for this study}

No. Parameter

$1 \quad$ Number of action potentials of the interpositus neuron in the CS-US interval.

2 Latency of the maximum instantaneous frequency for the interpositus neuron in the CS-US interval, with respect to the reference zero (ms).

3 Amplitude of the maximum instantaneous frequency for the interpositus neuron in the CS-US interval (spikes/s).

$4 \quad$ Latency of the first action potential of the interpositus neuron after the CS (ms).

5 Latency of the maximum instantaneous frequency for the interpositus neuron, with respect to $\mathrm{CS}$ presentation ( $\mathrm{ms}$ ).

6 Time of occurrence of the maximum instantaneous frequency for the interpositus neuron, with respect to the start of the $C R$ (ms).

7 Number of action potentials of the interpositus neuron in the interval between US presentation and the subsequent $100 \mathrm{~ms}$.

8 Latency of the maximum instantaneous frequency for the interpositus neuron between US presentation and the subsequent $100 \mathrm{~ms}$ (ms).

9 Amplitude of the maximum instantaneous frequency for the interpositus neuron between US presentation and the subsequent $100 \mathrm{~ms}$ (spikes/s).

10 Latency of the first action potential of the interpositus neuron after the US (ms).

11 Latency of the maximum instantaneous frequency for the interpositus neuron, with respect to US presentation (ms).

12 Time of occurrence of the maximum instantaneous frequency for the interpositus neuron, with respect to the start of the UR (ms).

13 Number of action potentials of the orbicularis oculi motoneuron in the CS-US interval.

14 Latency of the maximum instantaneous frequency for the motoneuron in the CS-US interval, with respect to the reference zero (ms).

15 Amplitude of the maximum instantaneous frequency for the motoneuron in the CS-US interval (spikes/s).

16 Latency of the first action potential of the motoneuron after the CS (ms).

17 Latency of the maximum instantaneous frequency for the motoneuron, with respect to CS presentation (ms).

18 Time of occurrence of the maximum instantaneous frequency for the motoneuron, with respect to the start of the $C R(\mathrm{~ms})$.

19 Number of action potentials of the motoneuron in the interval between US presentation and the subsequent $100 \mathrm{~ms}$.

20 Latency of the maximum instantaneous frequency for the motoneuron between US presentation and the subsequent $100 \mathrm{~ms}$ (ms).

21 Amplitude of the maximum instantaneous frequency for the motoneuron between US presentation and the subsequent $100 \mathrm{~ms}$ (spikes/s).

22 Latency of the first action potential of the motoneuron after the US (ms).

23 Latency of the maximum instantaneous frequency for the motoneuron, with respect to US presentation (ms).

24 Time of occurrence of the maximum instantaneous frequency for the motoneuron, with respect to the start of the UR (ms).

performed, with kinetic and kinematic parameters and sessions as repeated measures, coupled with contrast analysis when appropriate (Hair et al., 1998; Grafen and Hails, 2002). The orders $m$ (number of groups), $n$ (number of cats), and 1 (number of multivariate observations) were reported accompanying the $F$ statistic values. Wilk's $\lambda$ criterion, and its transformation to the $\chi^{2}$ distribution used in Matlab, were used to extract significant differences from MANOVA results. Regression analysis and computational algorithms of dynamic correlation were used to study the relationship between kinetic and kinematic variables. The corresponding statistical significance tests (i.e., Student's $t$ test and F statistic) were performed for the three parameters of correlation coefficient $(r)$, slope, and intercept of the regression line. These parameters were statistically significant if the resulting probability $P$, met the requirements of the hypothesis test: $P<p$, where $p<0.01$ was the predetermined statistical significance level (Belsley et al., 1980). Identical intervals were chosen for both eyelid CRs and instantaneous frequencies of interpositus neurons and orbicularis oculi motoneurons. The mean length of the intervals was within the range of 187-261 points, which corresponded to $179.51-250.55 \mathrm{~ms}$. The correlation coefficients $>0.1238$ were statistically significant, at least $95 \%(p<0.05)$, according to the criterion 


\section{Table 2. The 36 kinematic variables selected in this study}

\begin{tabular}{|c|c|}
\hline No. & Parameter \\
\hline 25 & Latency between the $C S$ and the start of the $C R(\mathrm{~ms})$. \\
\hline 26 & Latency between the start of the (R and the US (ms). \\
\hline 27 & Latency between the start of the ( $R$ and the minimum eyelid position value (ms). \\
\hline 28 & $\begin{array}{l}\text { Eyelid position amplitude at US presentation compared with the amplitude at the } \\
\text { start of the } C R\left({ }^{\circ}\right) \text {. }\end{array}$ \\
\hline 29 & $\begin{array}{l}\text { Minimum eyelid position amplitude, as compared with the amplitude at the start of } \\
\text { the }\left(R\left(^{\circ}\right) \text {. }\right.\end{array}$ \\
\hline 30 & Amplitude between the minimum and maximum eyelid velocity peaks ( $\%$ s). \\
\hline 31 & $\begin{array}{l}\text { Mean velocity (half the amplitude between the minimum and maximum eyelid } \\
\text { velocity peaks) }(\% / s) \text {. }\end{array}$ \\
\hline 32 & Latency between the minimum and maximum eyelid velocity peaks (ms). \\
\hline 33 & $\begin{array}{l}\text { Ratio between parameter } 28 \text { and the latency between the start of the CR and US } \\
\text { presentation }(\% / \mathrm{s}) \text {. }\end{array}$ \\
\hline 34 & Ratio between parameters 29 and $27(\% / s)$ \\
\hline 35 & Slope between US presentation and the minimum eyelid position points ( $\left.{ }^{\circ} / \mathrm{s}\right)$. \\
\hline 36 & Slope between the minimum and maximum eyelid velocity peaks $\left({ }^{\circ} / \mathrm{s}^{2}\right)$ \\
\hline 37 & Latency between the start of the CR and the start of the UR (ms). \\
\hline 38 & $\begin{array}{l}\text { Eyelid position amplitude at the start of the UR compared with the amplitude at the } \\
\text { start of the }\left(R\left(^{\circ}\right) \text {. }\right.\end{array}$ \\
\hline 39 & $\begin{array}{l}\text { Ratio between parameter } 38 \text { and the latency between the start of the } C R \text { and the } \\
\text { start of the UR }(\% / s) \text {. }\end{array}$ \\
\hline 40 & Slope between the start of the UR and the minimum eyelid position points ( $\%$ s). \\
\hline 41 & $\begin{array}{l}\text { Slope of the regression line that fits the eyelid position record between the start of } \\
\text { the (R and US presentation }(\% / s) \text {. }\end{array}$ \\
\hline 42 & $\begin{array}{l}\text { Intercept of the regression line that fits the eyelid position record between the start } \\
\text { of the CR and US presentation }\left({ }^{\circ}\right) \text {. }\end{array}$ \\
\hline 43 & $\begin{array}{l}\text { Slope of the regression line that fits the eyelid position record between the start of } \\
\text { the }(R \text { and the start of the UR }(\% / s) \text {. }\end{array}$ \\
\hline 44 & $\begin{array}{l}\text { Intercept of the regression line that fits the eyelid position record between the start } \\
\text { of the } C R \text { and the start of the } U R\left({ }^{\circ}\right) \text {. }\end{array}$ \\
\hline 45 & $\begin{array}{l}\text { Slope of the regression line that fits the eyelid position record between the start of } \\
\text { the }(R \text { and the minimum eyelid position }(\% / s) \text {. }\end{array}$ \\
\hline 46 & $\begin{array}{l}\text { Intercept of the regression line that fits the eyelid position record between the start } \\
\text { of the }\left(R \text { and the minimum eyelid position }\left(^{\circ}\right) \text {. }\right.\end{array}$ \\
\hline 47 & $\begin{array}{l}\text { Slope of the regression line that fits the eyelid velocity record between the mini- } \\
\text { mum and the maximum eyelid velocity }\left({ }^{\circ} / s^{2}\right) \text {. }\end{array}$ \\
\hline 48 & $\begin{array}{l}\text { Intercept of the regression line that fits the eyelid velocity record between the mini- } \\
\text { mum and the maximum eyelid velocity }(\% / s) \text {. }\end{array}$ \\
\hline 49 & Latency at the start of the downward phase of the blink (ms). \\
\hline 50 & Eyelid position amplitude at the start of the downward phase of the blink $\left({ }^{\circ}\right)$. \\
\hline 51 & Latency at US presentation (ms). \\
\hline 52 & Eyelid position amplitude at US presentation $\left(^{\circ}\right)$ \\
\hline 53 & Latency at the start of the eyelid position UR (ms). \\
\hline 54 & Eyelid position amplitude at the start of the $C R\left({ }^{\circ}\right)$ \\
\hline 55 & Time of occurrence of the minimum eyelid position peak (ms). \\
\hline 56 & Amplitude of the minimum eyelid position peak $\left({ }^{\circ}\right)$. \\
\hline 57 & Time of occurrence of the minimum eyelid velocity peak (ms). \\
\hline 58 & Amplitude of the minimum eyelid velocity peak ( $(\%)$ \\
\hline 59 & Time of occurrence of the maximum eyelid velocity peak (ms). \\
\hline 60 & Amplitude of the maximum eyelid velocity peak ( $\%$ s). \\
\hline
\end{tabular}

$r>\frac{2}{\sqrt{N p}}$, where $r$ is the Pearson's product moment correlation coefficient, and $N p$ is the total number of points of the correlated variables (Allen and Cady, 1982).

Additional details regarding off-line processing of collected physiological data for the construction of the hierarchical cluster tree are presented in supplemental Appendix S1 and Figure S1 A-E (available at www.jneurosci.org as supplemental material). Details regarding the rationale underlying the dynamic correlation functions and the relationships between the falling correlation and phase-modulation properties of cerebellar interpositus neurons are presented in supplemental Appendices S2 and S3 (available at www.jneurosci.org as supplemental material), respectively.

\section{Results}

Firing properties of cerebellar interpositus neurons and orbicularis oculi motoneurons during classical conditioning of eyelid responses

In those animals $(n=4)$ prepared for recording the firing activity of identified interpositus neurons, deep cerebellar nuclei were systematically explored to find unitary activity related with eyelid responses. The unitary activity was recorded during the random presentation of puffs of air $\left(10-100 \mathrm{~ms}, 1-3 \mathrm{~kg} / \mathrm{cm}^{2}\right)$ aimed at the ipsilateral cornea (Fig. 1A). This procedure took no more than five recording sessions. As confirmed later by the histological study, the dorsomedial part of the posterior interpositus nucleus was found to contain a high density of neurons related to reflexively evoked eyelid responses. Recorded neurons were identified by their antidromic activation (latency of $0.6-0.8 \mathrm{~ms}$ ) from the contralateral red nucleus (Fig. $1 \mathrm{~A}$ ). Although other deep cerebellar nuclei (mainly anterior interpositus and dentate nuclei) also contain neurons related to eyelid movements, we consider here only those located in the indicated area of the posterior interpositus nucleus.

Once the recording area was located, animals were classically conditioned using a delay paradigm (see Materials and Methods). Posterior interpositus neurons were recorded in the four animals across two habituation, 10 conditioning, and three extinction sessions. The mean number of neurons recorded per session was 2.9 (i.e., a mean of $41.37 \mathrm{~min}$ of recording per neuron). Interpositus neurons fired during downward movements (either conditioned or unconditioned eyelid responses) of the upper eyelid (Fig. 2A-C). Tones presented during the two habituation sessions evoked rather few reflex eyelid responses that appeared mainly during the first blocks of the habituation H01 session. During habituation sessions, interpositus neuron firing lagged the beginning of evoked eyelid responses by $20-40 \mathrm{~ms}$, but this lag decreased progressively across conditioning (see below). Their discharge rates were related to eyelid position (with a gain of $0.1-8.0$ spikes $\left.^{\circ} ; r<0.7 ; p \leq 0.05\right)$ and/or to eyelid velocity (0.05- 0.25 spikes $/{ }^{\circ}$ per second; $\left.r<0.7 ; p \leq 0.05\right)$. In accordance with previous reports (Van Kan et al., 1993; Gruart and DelgadoGarcía, 1994; Chen and Evinger, 2006), the recorded neurons $(n=131)$ were classified as type A. Posterior interpositus type B neurons $(n=43)$ were also antidromically activated from the red nucleus $(0.85-1.25 \mathrm{~ms})$ but presented a noticeable inhibition in their firing coinciding exactly with the downward displacement of the upper eyelid during reflexively evoked blinks (Gruart and Delgado-García, 1994; Gruart et al., 2000). Only those neurons located in the posterior interpositus nucleus, antidromically activated from the red nucleus and classified as type A, were included in this study.

In the other group of animals $(n=3)$, the facial nucleus was systematically explored in the search for motoneurons antidromically activated from the electrode implanted in the zygomatic branch of the facial nerve. As described previously (Shaw and Baker, 1985; Gruart et al., 2003) and confirmed histologically, orbicularis oculi motoneurons were concentrated in the dorsal subdivision of the facial nucleus. These motoneurons $(n=$ 110 ) were antidromically activated, with a mean latency of $2.25 \pm$ $0.31 \mathrm{~ms}$, and their firing started $\approx 10 \mathrm{~ms}$ before air-puff-evoked eyelid reflex responses. Once the recording area was located, animals were classically conditioned as indicated above. Orbicularis oculi motoneurons fired tonically during the performance of eyelid CRs (Fig. 2A,D,E). Thus, and as described previously (Trigo et 
A
$\frac{0}{0}$
$\frac{0}{0}$
$\frac{\pi}{0}$

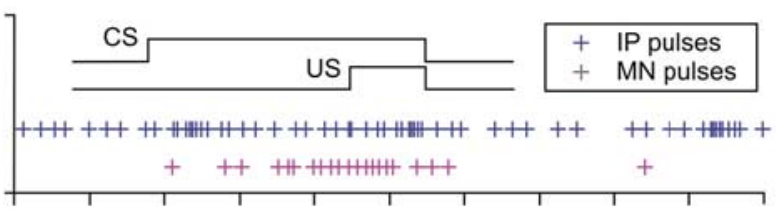

B
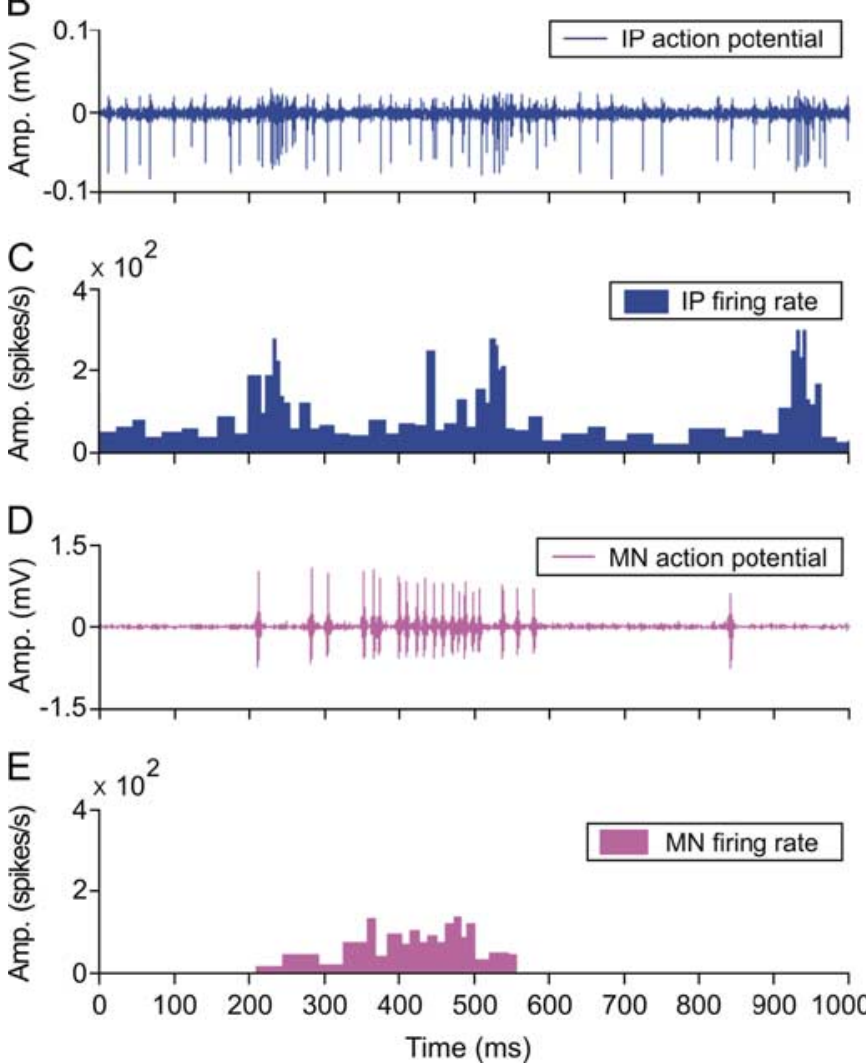

$\mathrm{F}$

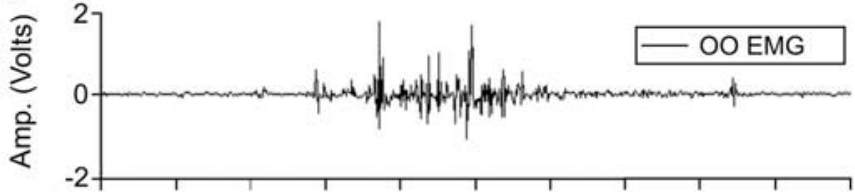

G
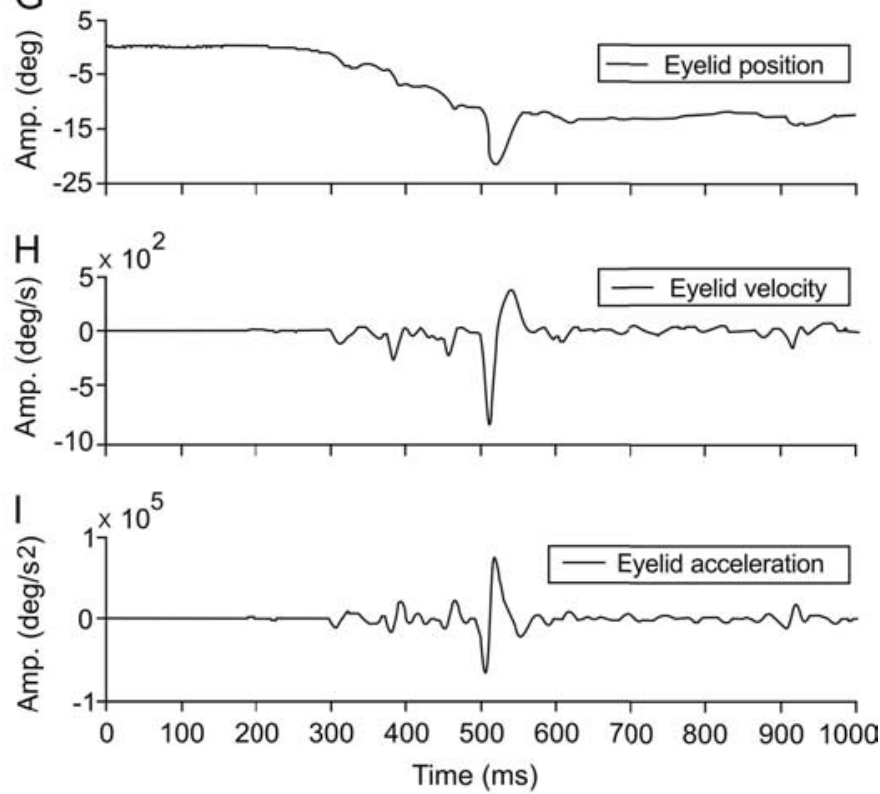

Figure 2. Global file representation. $A$, A diagrammatic representation of the delay conditioning paradigm with indication of the time presentation for $(S$ and US. Records illustrated in $\boldsymbol{B}$ - I were collected from the ninth conditioning session of two representative animals. The action potential pulses (IP pulses), marked with blue plus signs $(\boldsymbol{A})$, correspond to the direct representation of the neuronal activity in the cerebellar interpositus nucleus (IP action potential, in $\boldsymbol{B}$ ), and its respective instantaneous frequency (IP firing rate, in $\boldsymbol{C}$ ). Action potential pulses (MN pulses) recorded from an orbicularis oculi motoneuron are indicated with magenta plus signs $(\boldsymbol{A})$ and are the direct representation of the neuronal activity in the facial nucleus (MN action potential, in $\boldsymbol{D}$ ) and its corresponding instantaneous frequency (MN firing rate, in E). The 24 kinetic parameters determined in this study (see Table 1) were collected from the firing activities of identified orbicularis oculi motoneurons $(n=110)$ and cerebellar interpositus $(n=174)$ neurons recorded across the successive habituation $(n=2)$, conditioning $(n=10)$, and extinction $(n=3)$ sessions from seven cats. $\boldsymbol{F}-\boldsymbol{I}$, These traces illustrate the electromyographic activity of the orbicularis oculi muscle (00 EMG, in $\boldsymbol{F}$ ), the direct recording of the eyelid position by the magnetic field search-coil technique (G), and the estimated eyelid velocity $(\boldsymbol{H})$ and acceleration $(\boldsymbol{I})$ curves. The 36 kinematic parameters determined in this study (see Table 2 ) were collected from eyelid responses recorded across habituation, conditioning, and extinction sessions. For each of the physiological variables represented, the magnitude and the respective unit of measurement are indicated.

al., 1999), their discharge was related to eyelid position (with a gain of $4.5-11.3$ spikes $^{\circ}$; $r \geq 0.92 ; p \leq 0.01$ ) during CRs.

A total of 24 kinetic parameters (including latency, firing rate and profile, number of spikes during the CR, etc.) (Table 1) were systematically quantified from the selected interpositus neurons and orbicularis oculi motoneurons. For a quantitative determination of eyelid kinematics (Fig. $2 F-I$ ) during habituation, acquisition, and extinction, a total of 36 kinematic parameters were quantified from eyelid position, velocity, and acceleration profiles collected across the successive training sessions (for a complete relation of selected kinematic parameters, see Table 2).

Construction of a hierarchical cluster tree with kinetic neural commands and kinematic parameters collected during classical conditioning of eyelid responses

A piece of information still missing in learning studies relates to the coherence of recorded parameters regarding the actual learn- ing process. It is expected that, during the acquisition of a new motor ability, both kinetic commands and kinematic parameters should present an intrinsic homogeneity. Cluster analysis is a powerful tool for the analysis of such data (Taganova and Silakov, 1980; Banfield and Raftery, 1993; Hair et al., 1998; Ma et al., 2006). This algorithm for the processing of physiological recordings provides more homogeneity in the experimental database for the subsequent dynamic correlation analysis. The global files including the 60 selected parameters were clustered in an automated way, taking into account physiological criteria based on a kinetic-kinematic characterization of the activity of orbicularis oculi motoneurons and interpositus neurons and of the types of eyelid response (Tables 1, 2) (supplemental Appendix S1, available at www.jneurosci.org as supplemental material). This characterization was performed trial by trial, block by block, and session by session for selected animals $(n=5)$ during the successive experimental sessions (Fig. $3 A$ ). As explained in detail in 
A

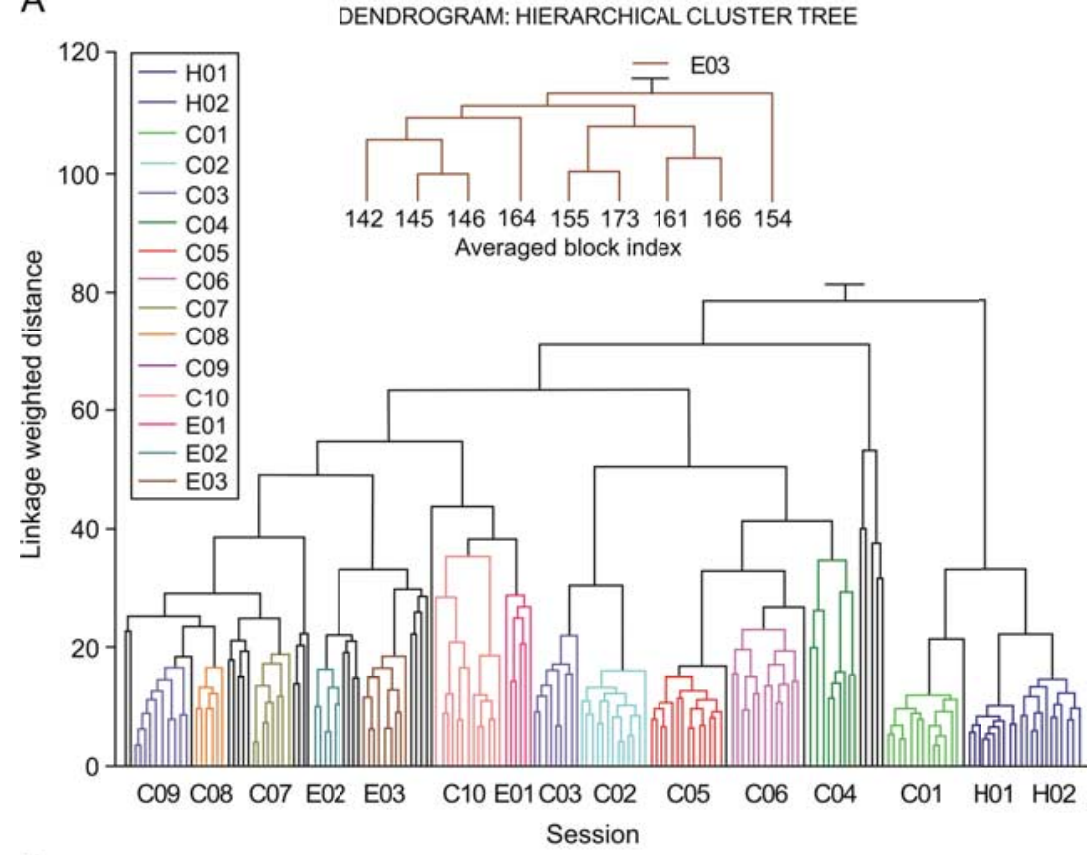

B

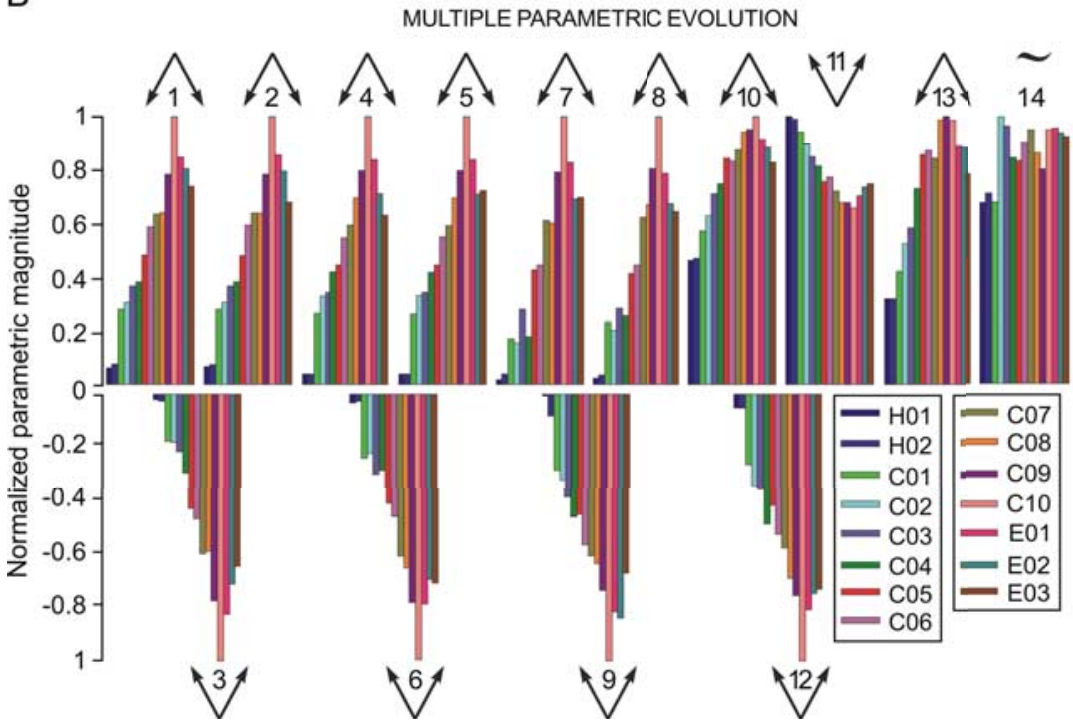

Figure 3. A representation of the hierarchical cluster tree and of multiparametric evolution of results collected across habituation, conditioning, and extinction sessions. $\boldsymbol{A}$, This dendrogram illustrates the hierarchical cluster tree constructed from data collected from five animals for each experimental session. A total of 63 orbicularis oculi motoneurons and 71 interpositus neurons were included in the analysis. Quantified parameters are listed in Tables 1 and 2. Each bar at the bottom of the dendrogram represents an averaged conditioning block (see Materials and Methods). The linkage-weighted distance between the objects is represented on the $y$-axis in arbitrary units. According to the illustrated results, a total of 30 clusters were obtained. The comparison depth was of 16 levels to both sides of the objective level, and the clusters were formed without specifying the maximum number of clusters. The $x$-axis represents, in colored lines (not black lines), the 15 statistically significant $\left(F_{(14,56,136)}>F_{(15,60,140)}, \ldots, F_{(29,116,150)}\right.$, with $N r=5$; Wilk's $\lambda=0.12$; and $F_{(14,56,136)}=20.1821 ; p<0.01$ ) clusters (corresponding to the 2 habituation, 10 conditioning, and 3 extinction sessions), which add up to 151 averaged blocks distributed in the 15 experimental sessions during the delay conditioning paradigm (H01-H02, 22 blocks; C01-C10, 108 blocks; and E01-E03, 21 blocks). The black lines represent the 29 averaged blocks that fall into the remaining 15 statistically nonsignificant clusters. An enlargement of the third extinction session (E03) is presented in the inset, and the order number assigned to each averaged block is indicated. $\boldsymbol{B}$, Multiple parametric evolution. A total of 14 parameters (4 kinetic and 10 kinematic, see Table 3) were included in this analysis. As illustrated in the inset, each color corresponds to a habituation, conditioning, or extinction session. Each set of color bars corresponds to the evolution of a given parameter (numbered from 1 to 14). Each color bar indicates the mean parametric value resulting from averaging all of the blocks ( $n=$ 12) of the same session, a procedure applied for each of the sessions. The $\Lambda$ arrows indicate that the parameter increases across conditioning sessions $(n=10)$ and then decreases across extinction sessions $(n=3)$. The $V$ arrows indicate the opposite. This parametric evolution is analogous to the one observed in typical learning curves using this classical conditioning paradigm. For this representation, the parameters have been normalized according to their maximum absolute values. Parameters $3,6,9$, and 12 kept their negative values because of the reference system adopted: namely, the eyes of the experimental subject are open at $0^{\circ}$ and totally closed at $25-30^{\circ}$.
Materials and Methods, each experimental (two habituation, 10 conditioning, and three extinction) session consisted of 12 blocks, and each block consisted of 10 trials. The computer program arranged the data in a total of 180 conditioning blocks ( 15 conditioning sessions $\times 12$ blocks) according to their significant homogeneity: namely, blocks within clusters were displayed close together when plotted geometrically, whereas different clusters were displayed far apart. Significant clusters $(n=15)$, illustrated by the bottom set of colored lines in Figure 3A, corresponded to blocks presenting significant coherent data $\left(F_{(14,56,136)}>F_{(15,60,140)}, \ldots\right.$, $F_{(29,116,150)}$, with $N r=5$; Wilk's $\lambda=0.12$, and $\left.F_{(14,56,136)}=20.18 ; p<0.01\right)$. These 15 significant clusters include 151 (i.e., $83.9 \%$ ) of the averaged blocks, whereas the remaining nonsignificant clusters ( $n=15$, clusters indicated by black lines) included only 29 (i.e., 16.1\%) of the averaged blocks. For the sake of clarity, the color code of significant clusters $(n=15$, including 151 blocks) shown in Figure 3A is maintained for the colored bars shown in Figure 3B, the colored curves illustrated in Figure $4 B$, and the colored circles shown in Figure 5, $A$ and $B$. Data corresponding to the nonsignificant clusters $(n=15)$ (Fig. 3A, black lines, including 29 blocks) were not further considered in this study.

The main outcome of the analytical procedure was that the hierarchical cluster tree was significantly consistent (cophenetic correlation coefficient, 0.97 ; the closer this value is to 1 , the better the clustering solution) with the actual conditioning sessions. For example, and given the similarity of the data collected in the corresponding trials and blocks, the two habituation sessions (H01, H02) were clustered close to the first conditioning session (C01). In addition, the first extinction session (E01) was clustered close to the 10th conditioning session (C10), whereas the following extinction sessions (E02, E03) were clustered close to the last four (7-10) conditioning sessions. Finally, middle experimental sessions ( $\mathrm{CO} 2-\mathrm{C} 06)$ formed by themselves a set of clusters.

Data organized in the matrix provided by cluster analysis allowed the selection of the most significant parameters representing the acquisition and extinction processes (Fig. 3B). A total of 14 representative parameters (4 kinetic and 10 kinematic) (Table 3) are depicted in Figure $3 B$. The evolution of these parameters across training was analogous to that observed in typical learning curves using this 
Table 3. The 14 physiological variables ( 10 kinematic and 4 kinetic) included in Figure $3 B$

\begin{tabular}{|c|c|}
\hline No. & Parameter \\
\hline 1 & $\begin{array}{l}\text { Eyelid position amplitude at US presentation compared with the amplitude at the } \\
\text { start of the } C R\left({ }^{\circ}\right) \text {. }\end{array}$ \\
\hline 2 & $\begin{array}{l}\text { Ratio between parameter } 1 \text { and the latency between the start of the CR and US } \\
\text { presentation }(\% / s) \text {. }\end{array}$ \\
\hline 3 & $\begin{array}{l}\text { Slope of the regression line that fits the eyelid position record between the start of } \\
\text { the } C R \text { and US presentation }(\% / s) \text {. }\end{array}$ \\
\hline 4 & $\begin{array}{l}\text { Eyelid position amplitude at the start of the UR compared with the amplitude at } \\
\text { the start of the } C R\left({ }^{\circ}\right) \text {. }\end{array}$ \\
\hline 5 & $\begin{array}{l}\text { Ratio between parameter } 4 \text { and the latency between the start of the } C R \text { and the } \\
\text { start of the UR }(\% / s) \text {. }\end{array}$ \\
\hline 6 & $\begin{array}{l}\text { Slope of the regression line that fits the eyelid position record between the start of } \\
\text { the } C R \text { and the start of the UR }(\% / s) \text {. }\end{array}$ \\
\hline 7 & $\begin{array}{l}\text { Intercept of the regression line that fits the eyelid position record between the } \\
\text { start of the CR and US presentation }\left({ }^{\circ}\right) \text {. }\end{array}$ \\
\hline 8 & $\begin{array}{l}\text { Intercept of the regression line that fits the eyelid position record between the } \\
\text { start of the }\left(R \text { and the start of the UR }\left(^{\circ}\right) \text {. }\right.\end{array}$ \\
\hline 9 & Eyelid position amplitude at US presentation $\left({ }^{\circ}\right)$ \\
\hline 10 & $\begin{array}{l}\text { Amplitude of the maximum instantaneous frequency for the interpositus neuron } \\
\text { in the (S-US interval (spikes/s). }\end{array}$ \\
\hline 11 & $\begin{array}{l}\text { Latency of the maximum instantaneous frequency for the interpositus neuron, } \\
\text { with respect to CS presentation (ms). }\end{array}$ \\
\hline 12 & Eyelid position amplitude at the start of the $\left(R\left(^{\circ}\right)\right.$. \\
\hline 13 & Number of action potentials of the motoneuron in the CS-US interval. \\
\hline 14 & Number of action potentials of the interpositus neuron in the CS-US interval. \\
\hline
\end{tabular}

classical conditioning paradigm (Gruart et al., 1995). For example, parameter 1 in Figure $3 B$ corresponded to the peak amplitude of the evoked CR. Note that this parameter increased steadily across conditioning and decreased progressively during the three extinction sessions $\left(F_{(14,56,136)}=123.68 ; p<0.01\right)$. The mean peak firing rate of interpositus neurons (parameter 10) also increased across conditioning and decreased during extinction $\left(F_{(14,56,136)}=749.46 ; p<0.01\right)$. Interestingly, the total number of spikes generated by facial motoneurons (parameter 13) during the CS-US interval increased across conditioning $\left(F_{(14,56,136)}=\right.$ $276.38 ; p<0.01)$. In contrast, the mean number of spikes generated by interpositus neurons in the CS-US interval (parameter 14) did not change significantly across conditioning, suggesting that the increase in their firing rate after CS presentation represented a reorganizing (instead of a net increase) of their mean spontaneous firing. Finally, an inversed evolution was obtained for the latency of the maximum instantaneous frequency for the interpositus neurons in the CS-US interval (parameter 11; $\left.F_{(14,56,136)}=297.99 ; p<0.01\right)$.

\section{The dynamic correlation function between interpositus neuron firing and eyelid conditioned responses}

Cluster analysis allowed us to homogenize the data collected during the different trials, blocks, and sessions with regard to the 60 selected parameters. One particular analysis that we performed after cluster analysis was to establish the dynamic correlation function between interpositus neuron firing and eyelid CRs. As illustrated in Figure $4 A$, the dynamic correlation analysis enabled us to determine the time of occurrence of the maximum correlation with respect to the zero reference point (i.e., the moment at which the CR started). The dynamic correlation analysis ranged, for each trial, from $200 \mathrm{~ms}$ before to $200 \mathrm{~ms}$ after the zero reference point (Fig. $4 A$, arrows). Details regarding the rationale underlying the dynamic correlation function are described in sup- plemental Appendix S2 (available at www.jneurosci.org as supplemental material).

For the curves represented in Figure $4 B$, the correlation functions corresponding to the trials taken from all of the blocks of the same session were averaged, session by session, for each animal across the successive conditioning sessions (C01-C10) (see color code in Fig. 4B). Dynamic correlation functions allowed describing how the correlation coefficients $(r)$ evolved during the successive sessions. Thus, we were able to determine whether the maximum correlation between interpositus neurons firing and eyelid CRs took place before or after the zero reference point (i.e., the moment at which the CR started).

Peak firing rate of interpositus neurons in response to CS presentations increased across conditioning, with a mean slope of 0.14 spikes/s per trial (from 150 spikes/s during the first conditioning session to 322 spikes/s during conditioning session 10). Interestingly, the time of occurrence of interpositus neuron peak firing rate decreased with respect to the zero reference point from $49.1 \mathrm{~ms}$ during the first conditioning session to $13.4 \mathrm{~ms}$ during conditioning session 10 . The increase in peak frequency, together with a decrease in its time of occurrence with respect to the zero reference point, caused a decrease in correlation coefficient values $(r=0.68$ for $\mathrm{C} 01$ to $r=0.51$ for $\mathrm{C} 10, p<0.01$; see $r$ values for each session from -100 to $+60 \mathrm{~ms}$ with respect to the zero reference point in Fig. $4 B$ ). In Figure $5 A$ is represented the evolution of the time to maximum correlation of the interpositus population with respect to the zero reference point for the 108 blocks that presented homogenous values according to the cluster analysis (slope, $-0.34 ; R=-0.92 ; p<0.01$ ). In the same way, Figure $5 B$ illustrates that the time to maximum correlation determined for interpositus neurons across the 10 conditioning sessions presented a linear relationship with the mean maximum correlation coefficient achieved during each block and conditioning session (slope, $0.0046 ; R=0.76 ; p<0.01$ ). According to this analysis, both the time to maximum correlation and the maximum correlation coefficient of interpositus neuron firing decreased across conditioning but always lagged the zero reference point (i.e., the start of the CR). Thus, the developed statistical algorithm indicated that the contribution of interpositus neurons might be related more to the modulation of eyelid responses than to their generation. Additional analysis performed regarding the functional relationships between interpositus neuron firing and eyelid CRs are detailed in supplemental Figure S2, $A$ and $B$, and Appendix S4 (available at www.jneurosci.org as supplemental material).

In contrast, the dynamic correlation function for orbicularis oculi motoneurons remained quasi-stationary and with high mean correlation coefficient values $\left(r_{\max }=0.68\right.$ for $\mathrm{C} 01$ and $r_{\max }=0.96$ for $\mathrm{C} 10 ; p<0.01$; data not illustrated) across conditioning sessions. According to these results, it can be proposed that orbicularis oculi motoneurons certainly encode eyelid kinematics at every instant of the dynamic correlation range. This inference is supported by the experimental fact that the discharge rate of orbicularis oculi motoneurons increased progressively across the learning process in relation to the increased amplitude of corresponding CRs. Thus, the discharge pattern for orbicularis oculi motoneurons correlates significantly $\left(F_{(9,27,98)}=42.46\right.$; $p<0.01$ ) with eyelid position during CRs in all of the conditioning sessions.

Figure 6 further illustrates the different functional properties of interpositus neurons (Fig. 6A) and orbicularis oculi motoneurons (Fig. $6 B$ ) with regard to the maximum correlation coefficients they reached during habituation, conditioning, and extinc- 
A
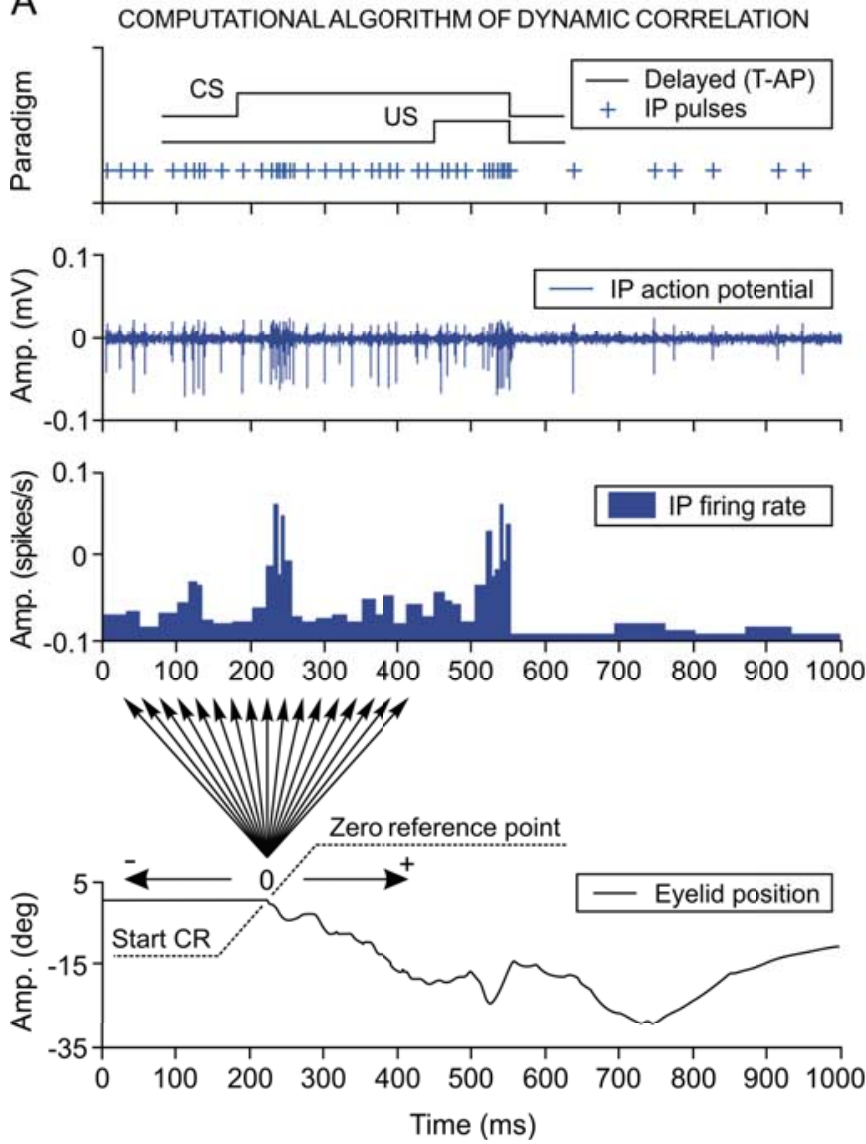

B DYNAMIC CORRELATION FUNCTION: INST. FREQ. vs. EYELID CR

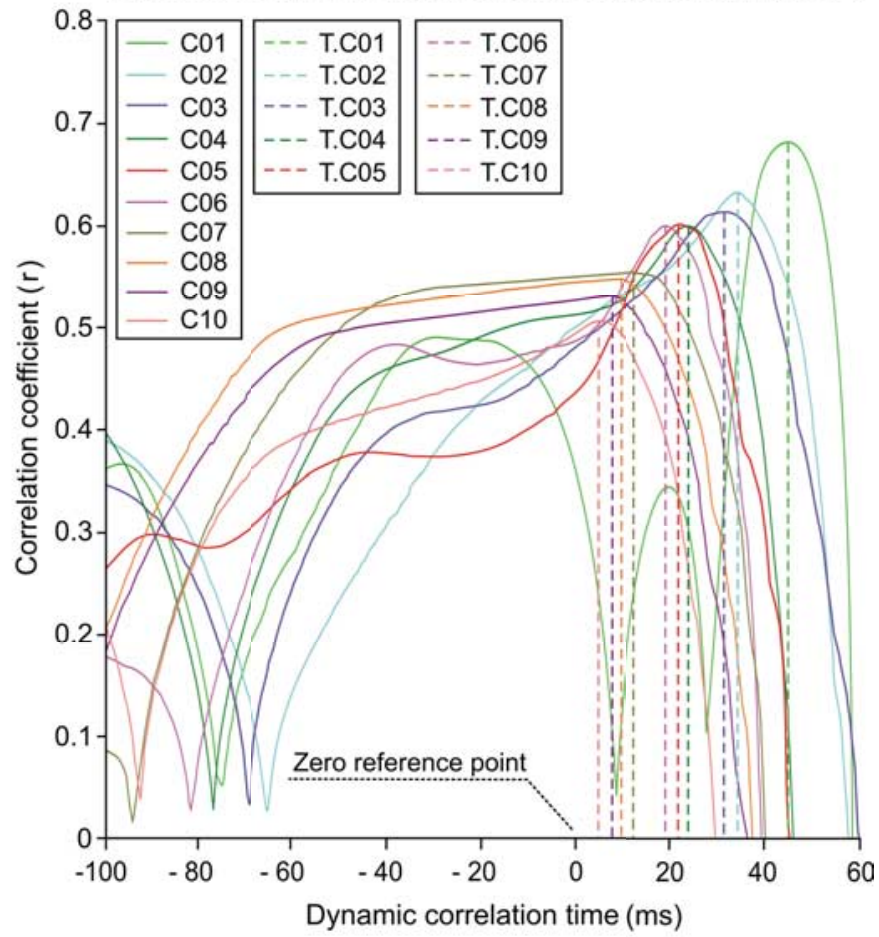

Figure 4. The dynamic correlation function between interpositus neuron firing and eyelid conditioned responses. $A$, Computational algorithm of the dynamic correlation. The implementation of the dynamic correlation algorithm during the ninth conditioning session is illustrated. A delay [tone-air puff (T-AP)] conditioning paradigm was used. Note the correspondence, in terms of time and magnitude, between three different representations of neuronal activity recorded in the cerebellar interpositus (IP) nucleus: (1) the temporal localization of the action potential pulses marked with plus signs; (2) the direct representation of the action potentials in the interpositus nucleus; and (3) the resultant instantaneous frequency (in spikes per second). A direct eyelid position record obtained simultaneously with neuronal activity is also shown. The start of the eyelid CR is taken as the zero reference point of the dynamic correlation, and the arrows indicate the dynamic correlation range ( $\pm 200 \mathrm{~ms})$. The corresponding regression lines and correlation coefficients were determined in steps of $1 \mathrm{~ms}$ (i.e., 400 regression lines from each trial, like the one illustrated). $\boldsymbol{B}$, Dynamic correlation functions. Ten dynamic correlation function curves are represented. Each representation corresponds to the average of all dynamic correlation curves obtained for the trials presenting (Rs $(n<10)$ and collected from all of the blocks $(n=12)$ of the same conditioning session (C01-C10) for all of the experimental subjects ( $n=4$ cats). The dynamic correlation interval illustrated extends over the instantaneous frequency representation from $-100 \mathrm{~ms}$ up to $+60 \mathrm{~ms}$ to both sides of the zero reference point. There is a significant $\left(F_{(9,27,98)}=161.54, p<0.01\right)$ decrease in the maximum correlation coefficient during conditioning sessions, in parallel with a decrease in the time of occurrence (T.K) of the maximum correlation. The broken lines indicate the T.K $K=C 01$, $\ldots,(10)$, which are always located to the right of the zero reference point, as indicated in $A$. Note that correlation coefficients obtained across the successive sessions were statistically significant $\left(F_{(9,27,98)}=37.56 ; p<0.01\right)$, although their values show only a slight coupling $(r$ coefficient $<0.7)$ between neuronal activity recorded at the interpositus nucleus and eyelid position during CRs.

tion sessions, and the time these maximum values were achieved with respect to the zero reference point (indicated by the dashed line a). On the color raster display illustrated in Figure $6 \mathrm{~A}$, it can be observed that the maximum correlation coefficient evolved from relatively high coefficient values $(r<0.7)$ to intermediate coefficient values $(r \approx 0.5)$. This is clearly indicative of the progressive diminution of correlation across conditioning. At the same time, the dashed line $\mathrm{b}$ indicates that maximum $r$ values were reached at decreasing (i.e., shorter) times with regard to the zero reference point. In contrast, the raster color display illustrated in Figure $6 B$ indicates that orbicularis oculi motoneurons presented high correlation values $(r=0.68-0.96)$ during all of the conditioning sessions. Importantly, their dynamic correlation times were always set at $\approx 10 \mathrm{~ms}$ before the zero reference time (dashed line b).

\section{Oscillatory and phase inversion properties of interpositus} neurons and orbicularis oculi motoneurons

Figure 7, $A$ and $B$, illustrates the cumulative trapezoidal integral of three representative interpositus neurons (IP1-IP3) and a rep- resentative orbicularis oculi motoneuron during the first (C01) (Fig. $7 A$ ) and the 10th $(\mathrm{C} 10)$ (Fig. $7 B$ ) conditioning sessions. It should be noticed that all of the neurons presented an increasing profile and that they showed some slight and relative variations around the local and global maximum instantaneous frequency values. We defined three equivalence times (L1-L3) at the points at which interpositus neuron type IP2 and motoneurons crossed their lines. The equivalence times meet the requirement $\mathrm{L} 2(\mathrm{C} 01)>\mathrm{L} 2(\mathrm{C} 10)$ and $\mathrm{L} 3(\mathrm{C} 01)>\mathrm{L} 3(\mathrm{C} 10)$ in the CS-US interval during the conditioning sessions, given the following experimental facts: (1) an increase in the amplitude of the maximum instantaneous frequency of interpositus neurons ( $\mathrm{C} 01$, 151.5 spikes/s; C10, 322.6 spikes/s); (2) a decrease in the time of occurrence (C01, $49.1 \mathrm{~ms}$; C10, $13.4 \mathrm{~ms}$ ) of the maximum instantaneous frequency for interpositus neurons, and (3) a progressive increase in the discharge rate of orbicularis oculi motoneurons across the learning process (smaller in $\mathrm{C} 01$ and larger in $\mathrm{C} 10$ ).

The presence of an oscillatory behavior in the firing of interpositus neurons and orbicularis oculi motoneurons was evidenced by high-pass filtering the traces illustrated in Figure 7, A 
A

CORRELATION EVOLUTION DURING CONDITIONING SESSIONS

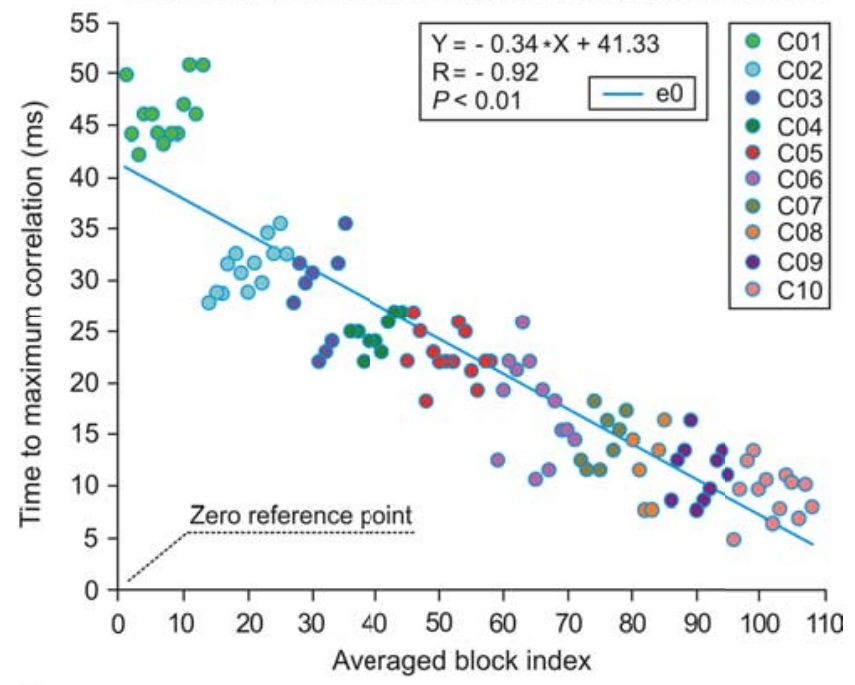

B

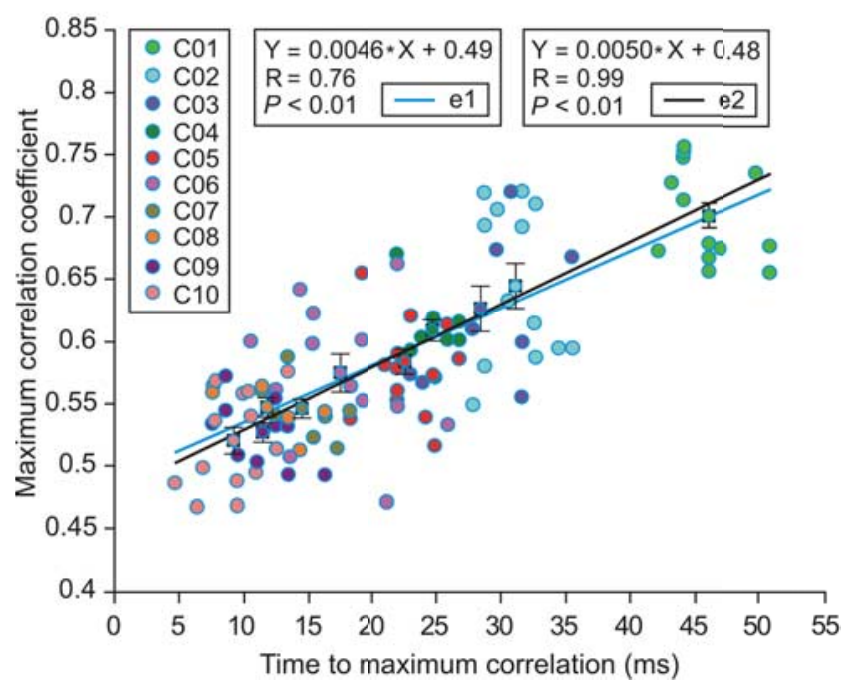

Figure 5. Evolution of the correlation coefficient of linear regression analysis between interpositus neuron firing and eyelid conditioned responses across conditioning sessions. A, Falling time to maximum correlation coefficient across sessions. On the $x$-axis are represented the successive blocks across conditioning sessions ( $(01-\mathrm{C} 10,108$ blocks) that presented significant (Wilk's $\lambda=0.19 ; F_{(9,36,98)}=15.24 ; p<0.01$ ) homogeneity values with their corresponding cluster. Blocks are arranged by their index number. The color code indicates the block session. The $y$-axis represents the latency (in milliseconds) to the maximum correlation time. Each colored circle corresponds to the mean time of occurrence of the maximum correlation associated to each averaged block. The averaged block indexes are sorted from 1 to 108 along the

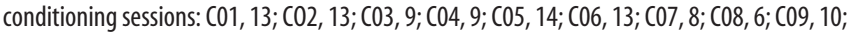
$(10,13$. The simple regression model used for this representation indicates a high correlation $(r=-0.92 ; p<0.01)$. Note the negative sign of both the regression coefficient $(R)$ and the slope $(-0.34)$ in the linear equation $e 0$ (see inset). $\boldsymbol{B}$, Relationships between the time to maximum correlation coefficient and maximum correlation coefficient. This plot represents the mean maximum correlation coefficients ( $y$-axis) corresponding to each averaged block with respect to the mean time of occurrence of the maximum correlation coefficient $(x$-axis). The color code indicates the corresponding conditioning session (C01-C10). The linear equation $e 1$ (see middle inset) is applied to the set of circles associated to the averaged blocks, whereas the linear equation $e 2$ is applied to the 10 -square/circle subset representing the mean values per session. For each mean value, the SE is indicated.

and $B$. The relative variation curves obtained after the high-pass filtering process (Fig. $7 C, D$ ) presented oscillatory and phaseinversion properties. By phase inversion, we mean the transition from a partial phase difference $(\approx \pi / 2$ for C01, i.e., a cosine-type curve for motoneurons and a sine-type curve for interpositus neurons) to a total phase difference ( $\approx \pi$ for C10, i.e., a cosinetype curve for motoneurons and a minus cosine-type curve for interpositus neurons). These results allow proposing a modulatory role of interpositus neurons in the final common pathway for the eyelid system (i.e., the motoneuronal pool) that, by progressively inverting phase information, modulate or reinforce eyelid motor responses inversely (not opposed) to the contribution of orbicularis oculi motoneurons.

The relative power spectra illustrated in Figure 7, $E$ and $F$, correspond to the curves shown in Figure 7, $C$ and $D$, respectively. The predominance of spectral components observed $\sim 20$ $\mathrm{Hz}$ was probably attributable to the $50 \mathrm{~ms}$ mean period characteristic of eyelid kinematics, as evidenced in the unconditioned responses (for both motoneuron firing and eyelid position) illustrated in Figure 7, $C$ and $D$. In fact, an oscillation at the same $(\approx 20 \mathrm{~Hz})$ dominant frequency has been observed in eyelid acceleration traces and in the EMG activity of the orbicularis oculi muscle (Domingo et al., 1997). It should also be noticed that, during the first conditioning session (C01) (Fig. 7C), the oscillation amplitude of the motoneuron relative variation function was more significant $\left(F_{(9,54,98)}=170.26 ; p<0.01\right)$, both in the CS-US interval and after US presentation, than that of interpositus neurons. In contrast, the oscillation amplitude of the interpositus neuron relative variation function increased progressively across the learning process, reaching significant values $\left(F_{(9,54,98)}=59.51 ; p<0.01\right)$ during the 10th conditioning session (Fig. $7 D$ ) but only during the CS-US interval.

\section{Discussion}

Design of optimized experimental and analytical tools for the study of cerebellar functions

The multivariate cluster analysis is an optimal analytical tool to link the kinetic neural commands (i.e., motor and premotor neuronal activities computed from different quantitative parameters) and kinematic (i.e., motor activities computed from EMG and actual movement) parameters during motor learning and used here allows us to determine the intrinsic coherence of collected data. For this, we developed the necessary computer programs and algorithmic procedures to deal with such a huge amount of data (60 parameters quantified across 15 experimental sessions collected from 7 experimental animals). The main result indicated that up to 151 blocks could be correctly assigned to the corresponding experimental (habituation, conditioning, or extinction) session, and only data collected from 29 blocks were discarded because of their low homogeneity with the corresponding session. Importantly, these positive results indicated that neural firing properties recorded from different animals during the same conditioning paradigm can be correctly assigned to the corresponding experimental session (i.e., in agreement with the actual CR evoked during the CS-US interval). Although we have checked here the firing characteristics of only orbicularis oculi motoneurons and interpositus neurons, it can be proposed that the intrinsic coherence demonstrated between kinetic and kinematic properties strongly suggests the presence of a functional neuronal state involving many different cerebral centers evoked by the learning process (Delgado-García and Gruart, 2002). An additional advantage of this experimental approach is that, once collected data were properly arranged according to the hierarchical cluster tree (and that nonsignificant data were rejected), it was possible to determine analytically the multiple and coherent evolution of kinetic and kinematic parameters (Fig. 3B), the dynamic correlation function relating motoneurons and interpositus fir- 
A
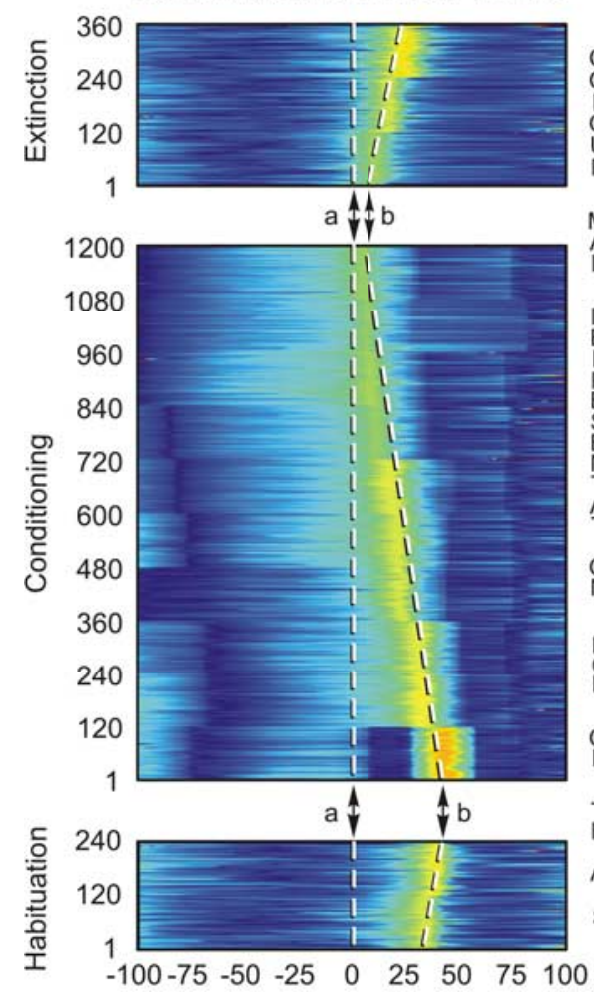

Dynamic correlation time (ms)

\section{B}
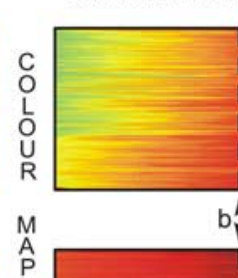

11

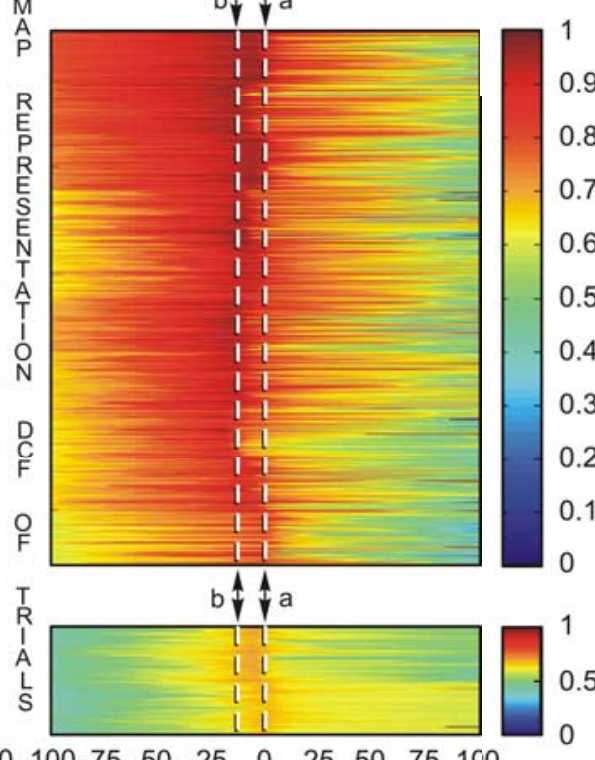

Dynamic correlation time (ms)

Figure 6. A color map representation of the dynamic correlation evolution across habituation, conditioning, and extinction sessions for cerebellar interpositus neurons and orbicularis oculi motoneurons. A, A two-dimensional map resulting from dynamic correlation between eyelid position during (Rs and the instantaneous firing rate of identified cerebellar interpositus neurons. The map represents the dynamic evolution of the correlation coefficients ( $0-1)$ across two habituation (2 neurons, 240 trials), 10 conditioning (17 neurons, 1200 trials), and three extinction ( 5 neurons, 360 trials) sessions, with respect to the dynamic correlation time which, in this case, is of $100 \mathrm{~ms}$, on both sides of the start of the eyelid CR ( 0 time, dashed line a). Note a reduction in the time of occurrence of the maximum correlation in parallel with a slight decrease (shades of orange degrading to shades of green, going through yellow) in the maximum correlation coefficient across conditioning (indicated by the dashed line b). $\boldsymbol{B}$, A two-dimensional map resulting from dynamic correlation between eyelid position during (Rs and the instantaneous firing rate of identified orbicularis oculi motoneurons. The map represents the dynamic evolution of the correlation coefficients $(0-1)$ across two habituation ( 5 neurons), 10 conditioning (21 neurons), and three extinction ( 7 neurons) sessions. The correlation coefficient values remained high during learning and were predominant around the $10.4 \pm 4 \mathrm{~ms}$ (indicated by the dashed line b) before the start of the CR (0 time, dashed line a).

ing to eyelid CRs (Fig. 4B), the falling correlation property of the interpositus nucleus across the successive training sessions (Fig. $5)$, the time and significance of the linear relationships between these variables (Fig. 6), and, finally, the oscillatory and phaseinversion properties of orbicularis oculi motoneurons and interpositus neurons with regard to acquired CRs (Fig. 7). Thus, these novel (experimental and analytical) approaches to the study of actual neuronal mechanisms underlying the acquisition of new motor abilities will certainly contribute to the better understanding of brain functioning in alert behaving animals.

\section{The posterior interpositus nucleus as an enhancer of acquired motor abilities}

As already stated (Gruart and Delgado-García, 1994) and further confirmed here, the discharge rate of interpositus neurons seems to mirror the position and/or the velocity of eyelid CRs and increases during the CS-US interval in parallel with the amplitude of the CR. According to the present results, the maximum instantaneous frequency reached by type A (Gruart et al., 2000) interpositus neurons increased during the successive conditioning sessions, reaching mean amplitude values of $\approx 150$ spikes/s during the first (C01) conditioning session and up to $\approx 320$ spikes/s during the 10th (C10) session. The slope of this increase (0.14 spikes/s per trial) is similar to values reported for orbicularis oculi motoneurons (Trigo et al., 1999), interpositus neurons (Gruart et al., 2000), and hippocampal CA3 and CA1 pyramidal neurons (Múnera et al., 2001) during associative learning using both delay and trace conditioning procedures in alert behaving cats. This important finding reinforces the hypothesis that associative learning using classical conditioning procedures evokes a functional state in many different neuronal centers, characterized by a common increase in firing rate, and not necessarily related with the specific function fulfilled by each neural site (Delgado-García and Gruart, 2002).

The sustained increase in mean peak firing rate presented by the interpositus neuronal pool across conditioning was in parallel with a decrease in the mean time of its occurrence $(\approx 49 \mathrm{~ms}$ for the first conditioning session to $\approx 13 \mathrm{~ms}$ by the 10 th session) with respect to the start of the CR. The increase in firing rate, in association with the decrease in its mean time of occurrence, caused the maximum correlation coefficient between interpositus neuron activity and eyelid CR to decrease $(r=$ 0.68 during the first conditioning session to $r=0.51$ during the 10th). As a result, maximum correlation coefficient values between instantaneous interpositus firing and eyelid position during the CS-US interval always lagged $(\approx 45 \mathrm{~ms}$ during the first conditioning session to $\approx 5 \mathrm{~ms}$ during the 10th) the zero reference point (i.e., the start of the CR). The foregoing allows us to affirm that interpositus neurons do not directly encode eyelid kinematics, i.e., their contribution is only weakly significant in the dynamic correlation range. Nevertheless, slight correlation $(r<0.7)$ values are not necessarily indicative of an absence of functional relationships between the involved variables. At the same time, a high correlation does not necessarily indicate a causal relationship (Granger, 1980; Baccala and Sameshima, 2001). In practice, the significance of the correlation coefficient is usually checked, at the desired level of statistical confidence, by calculating the residual cross-correlation. It must be mentioned here that the cross-correlation function at zero time lag is the linear correlation coefficient, an index frequently used to measure the linear interdependence between two variables (Belsley et al., 1980; Allen and Cady, 1982). According to the present results, it is important to indicate that the difference between occurrence of peak firing rate of interpositus neurons and that of maximum correlation coefficient was always positive (i.e., $\approx 4 \mathrm{~ms}$ for the first conditioning session and $\approx 8.5$ $\mathrm{ms}$ for the 10th): namely, the time of occurrence of the maximum correlation coefficient was always shorter than the time of occur- 
rence of the maximum instantaneous frequency, suggesting that interpositus firing does not encode directly CR kinematics.

Other experimental evidence, such as the increase in the maximum instantaneous frequency of cerebellar interpositus neurons and the decrease in the time of occurrence of the maximum frequency after the start of the CR across the 10 conditioning sessions, suggested a slightly significant covariance between the correlated variables. It should be noticed that the dynamic correlation curves (illustrated in Fig. $4 B$ ) were irregular under the same experimental conditions, indicating a limited, or at least an uncertain, influence of interpositus neurons on the generation of learned responses. The statistical algorithm developed here indicates that the contribution of this neuronal population can be interpreted better on the assumption that its members enhance eyelid responses. Thus, the role of interpositus neurons might be related more to the modulation of eyelid responses than to their generation.

In relation to eyelid responses, the interpositus area studied here corresponded to the dorsomedial part of the posterior division of the nucleus. This area coincides with previous mapping studies, performed with electrophysiological techniques in behaving cats (Gruart and DelgadoGarcía, 1994; Gruart et al., 2000) and monkeys (Van Kan et al., 1993). The same area was labeled with retrograde transneuronal tracing of rabies virus injected in the upper eyelid of the rat (Morcuende et al., 2002). In contrast, the rabbit anterior interpositus nucleus has been assumed as the site in which this type of associative learning is acquired and stored (Christian and Thompson, 2003; Krupa et al., 1993). It is possible that lesion studies performed in the anterior interpositus (Yeo et al., 1985; Krupa et al., 2003) did affect axons originated in the posterior part of the nucleus. Moreover, as reported in previous studies (Gruart et al., 1995, 2000; Trigo et al., 1999; Jiménez-Díaz et al., 2004), there are important functional differences between rabbits and cats. The more important is that the retractor bulbi system seems not to be involved in the generation of CRs in cats (Trigo et al., 1999). Thus, minor differences in the location of eyelid-related neurons in the interpositus nuclei could be expected between species.

In contrast, and according to the present results, it can be stated that orbicularis oculi motoneurons certainly encode eyelid kinematics directly at every instant
A

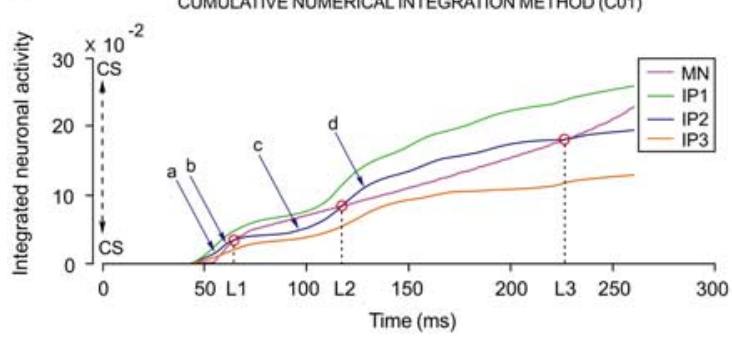

B

CUMULATIVE NUMERICAL INTEGRATION METHOD (C10)

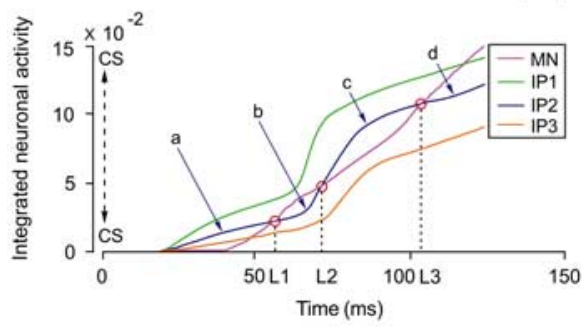

C

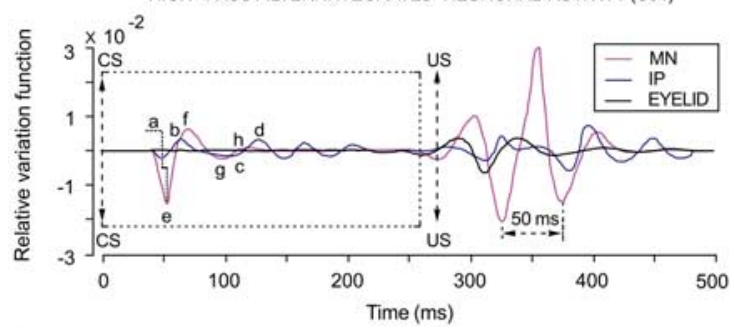

D HIGH - PASS FILTER: INTEGRATED NEURONAL ACTIVITY (C10)

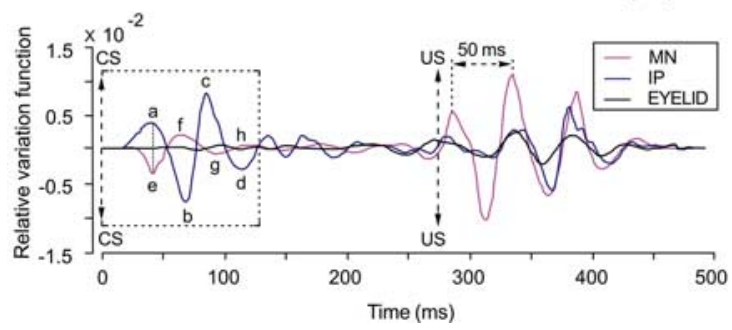

FOURIERTRANSFORMS (C10)

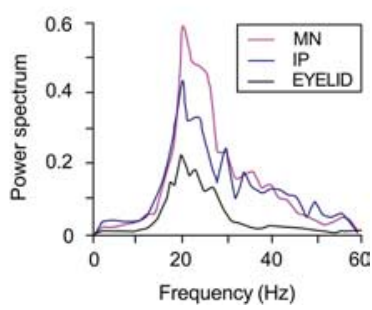

Figure 7. Oscillatory and phase-inversion properties of cerebellar interpositus neurons. $A, B, A$ representation of the cumulative numerical integration method. Three of the illustrated traces correspond to the averaged integrated neuronal activity of identified cerebellar interpositus (IP; see color codes in the inset) neurons, and the fourth trace represents the integrated neuronal activity of a selected orbicularis oculi motoneuron (MN; see code in the inset). Data were collected from the first $(A)$ and the 10th $(\boldsymbol{B})$ conditioning session, respectively. In each case, CS presentation (time 0$)$ and the equivalence times $(\mathrm{L} 1, \mathrm{L2}$, and $\mathrm{L} 3$ ) of integrated neuronal activity are indicated. Note that, for IP2 traces, the equivalence times accord with L2.C01 > L2.C10 and L3.C01 > L3.C10. For session C01, the IP2 trace represents $63.7 \%$ of the analyzed data, and the IP1 and IP3 traces represent 24.1 and $12.2 \%$, respectively. For session C10, the IP2 trace represents $68 \%$, the IP1 trace $12.6 \%$, and the IP3 trace $19.4 \%$. C, D, High-pass filtering of the integrated neuronal activity. Oscillatory curves (relative variation functions) resulting from high-pass filtering ( $-3 \mathrm{~dB}$ cutoff at $5 \mathrm{~Hz}$ and zero gain at $\approx 15 \mathrm{~Hz}$ ) of integrated neuronal firing activities illustrated in $(\boldsymbol{A}, \boldsymbol{B})$ and of eyelid position corresponding to the same set of records. In $C$, the motoneuron (magenta trace) and the interpositus neuron (blue trace) curves show a phase difference ( $\approx \pi / 2$, as indicated by the crooked dashed line) during their oscillations in the CS-US interval, which remains during eyelid unconditioned responses to US presentation. Note that, in fact, components a- $d$ (from interpositus neuron traces as shown in $\boldsymbol{A}-\boldsymbol{C}$ ) are partially out of phase with components $\mathrm{e}-\mathrm{h}$ (from MN traces, as indicated in $\boldsymbol{C}$, respectively. In $\boldsymbol{D}$, motoneuron and interpositus neuron curves present a phase difference $(\approx \pi$, as indicated by the straight dashed line) during their oscillations in the CS-US interval. Note that, in this case, components a- $d$ are totally out of phase with components $e-h$, respectively. In contrast, during the occurrence of eyelid unconditioned responses, both motoneuron and interpositus neuron variation curves show oscillations with a similar phase. $E$, $F$, Fast Fourier transforms. Power spectra for the oscillating curves shown in $\boldsymbol{C}$ and $\boldsymbol{D}$, respectively. Note that the three illustrated spectra, during both the first $(\boldsymbol{E}, \mathbf{C 0 1})$ and 10 th $(\boldsymbol{F}, \mathbf{C 1 0})$ conditioning sessions, presented a significant predominance of spectral components at $\approx 20 \mathrm{~Hz}$ and significant differences between their power spectra for both interpositus neurons (interpositus neurons, $F_{(9,54,98)}=216.28 ; p<0.01$ ) and orbicularis oculi motoneurons (motoneurons, $F_{(9,54,98)}=225.48 ; p<0.01$ ). 
of the dynamic correlation range. This inference is supported by the experimental fact that the discharge rate of these facial motoneurons increased progressively across the learning process, with a relative refractory period (minimum interspike time interval) that decreased progressively in the CS-US interval and reached values slightly $>3 \mathrm{~ms}$ immediately after US presentation (i.e., a peak firing rate of $\approx 330$ spikes/s). Thus, an orbicularis oculi motoneuronal discharge pattern that correlated significantly with eyelid position during CRs in all of the conditioning sessions was obtained.

\section{Phase-inversion properties and modulating role of posterior} interpositus neurons in learned motor responses

The presence of oscillation in the relative variation functions of interpositus neurons is in evident concordance with reports regarding the wavy form CRs, formed in the cat by a succession of small waves (Domingo et al., 1997; Trigo et al., 1999). These waves are present not only in the position, velocity, and acceleration profiles of eyelid traces (Domingo et al., 1997) but have also been noticed in the EMG activity of the orbicularis oculi muscle (Domingo et al., 1997), in the firing activity of facial motoneurons innervating this muscle (Trigo et al., 1999), in the resting potential of facial motoneurons recorded both in vivo (Trigo et al., 1999) and in vitro (Magarinos-Ascone et al., 1999), and, finally, in the firing activities of motor cortex neurons during CRs evoked in behaving cats (Aou et al., 1992).

According to the high correlation coefficients between eyelid CRs and the instantaneous frequency of orbicularis oculi motoneurons, these small waves can be directly related to the motoneuron relative variation function components. They may, then, be partially (in session C01) or totally (in session C10) out of phase compared with relative variation function components of interpositus neurons. A sequential and out-of-phase release of the activity of interpositus neurons would certainly be helpful for a proper performance of consolidated eyelid CRs. Thus, we have to assume that interpositus neurons might play a role related more to phase modulation of the oscillation already observed in eyelid motor responses than to its generation. Accordingly, it could be necessary to have a neural site taking charge of compensating the oscillation of the lid, mostly during the acquisition of a new motor ability (Delgado-García and Gruart, 2002). In this sense, the increase in peak firing frequency and the decrease in its mean time of occurrence described here for interpositus neurons could contribute to its role as a neuronal phase-modulating device: namely, peak interpositus neuron firing should reach the orbicularis oculi motoneuron pool at the time when these motoneurons initiate their repolarization process, facilitating their repetitive firing in a decreasing time interval across conditioning sessions (Trigo et al., 1999; Delgado-García and Gruart, 2002) (Fig. 8). This phase-modulating device could play a damping role in eyelid performance, particularly during the process of acquiring new motor abilities (Jiménez-Díaz et al., 2004), a proposal already put forward by others (Thach et al., 1992). In this regard, it has been recently reported that disturbances in fast cerebellar oscillation in the cerebellar cortex could be related to cerebellar ataxia (Cheron et al., 2005). A mathematical demonstration of the relationships between falling correlation and phasemodulation properties of interpositus neurons is presented in supplemental Appendix S3 (available at www.jneurosci.org as supplemental material).

In summary, the double role of posterior interpositus neurons as an enhancer of facial motoneuron firing and as a damping device could help to explain cerebellar contribution to the proper
REINFORCING ROLE OF IPn DURING THE LEARNING PROCESS
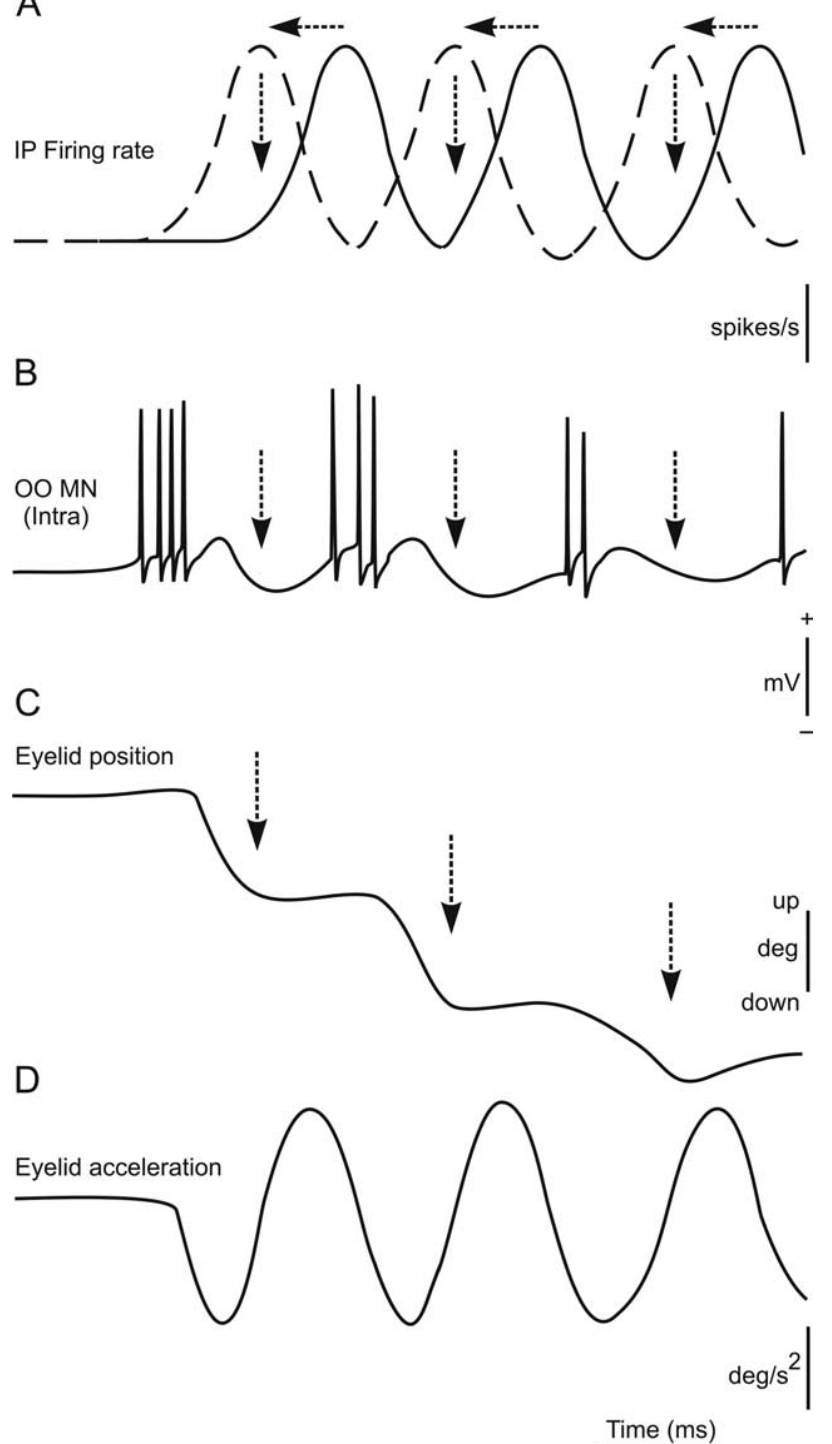

Figure 8. A functional representation of the reinforcing role of interpositus neurons during the learning (acquisition) process. $\boldsymbol{A}-\boldsymbol{D}$, From top to bottom are represented the firing rate (in spikes per second) of interpositus neurons (IP) (A), the typical firing of orbicularis oculi motoneurons (00) ( $\boldsymbol{B}$; in millivolts) during the performance of an eyelid CR (see Trigo et al., 1999) and the corresponding eyelid position $(\boldsymbol{C}$; in degrees) and acceleration $(\boldsymbol{D}$; in degrees per squared second) traces. Note that the latency of peak interpositus firing decreases across conditioning and becomes out of phase with motoneuronal firing. Thus, at given a latency of $4 \mathrm{~ms}$ for interpositus action potentials to reach the motoneuron pool (Trigo et al., 1999), interpositus firing would facilitate a quick repolarization process of orbicularis oculi motoneurons, reinforcing their tonic firing during CR performance.

performance of ongoing motor responses (mainly during the acquisition process) and to its proper timing (Welsh and Harvey, 1991; Delgado-García et al., 2002; Medina et al., 2002; Seidler et al., 2002; Koekkoek et al., 2003).

\section{References}

Allen DA, Cady FB (1982) Analyzing experimental data by regression. Belmond, CA: Wadsworth.

Aou S, Woody CD, Birt D (1992) Changes in the activity of units of the cat motor cortex with rapid conditioning and extinction of a compound eyeblink movement. J Neurosci 12:549-559.

Baccala LA, Sameshima K (2001) Overcoming the limitations of correlation analysis for many simultaneously processed neural structures. Prog Brain Res 130:33-47. 
Banfield J, Raftery A (1993) Hierarchical model-based clustering for large datasets. Biometrics 49:803-821.

Belsley DA, Kuh E, Welsch RE (1980) Regression diagnostics: identifying influential data and sources of collinearity. New York: Wiley.

Berman AL (1968) The brain stem of the cat: a cytoarchitectonic atlas with stereotaxic coordinates. Madison, WI: University of Wisconsin.

Bracha V, Zhao L, Irwin K, Bloedel JR (2001) The human cerebellum and associative learning: dissociation between the acquisition, retention and extinction of conditioned eyeblinks. Exp Brain Res 136:41-49.

Carey MR, Lisberger SG (2002) Behavioral analysis of gain control for smooth pursuit eye movements. Neuron 35:223-226.

Chen FP, Evinger C (2006) Cerebellar modulation of trigeminal reflex blinks: interpositus neurons. J Neurosci 26:10569-10576.

Cheron G, Servais L, Wagstaff J, Dan B (2005) Fast cerebellar oscillation associated with ataxia in a mouse model of Angelman syndrome. Neuroscience 130:631-637.

Christian KM, Thompson RF (2003) Neural substrates of eyeblink conditioning: acquisition and retention. Learn Mem 10:427-455.

Delgado-García JM, Gruart A (2002) The role of interpositus nucleus in eyelid conditioned responses. Cerebellum 1:289-308.

Domingo JA, Gruart A, Delgado-García JM (1997) Quantal organization of reflex and conditioned eyelid responses. J Neurophysiol 78:2518-2530.

Eccles JC, Ito M, Szentagothai J (1967) The cerebellum as a neuronal machine. Berlin: Springer.

Evinger C, Manning KA, Sibony PA (1991) Eyelid movements. Mechanisms and normal data. Invest Ophthalmol Vis Sci 32:387-400.

Gormezano I, Kenoe EJ, Marshall BS (1983) Twenty years of classical conditioning research with rabbits. Prog Psychobiol Physiol 21:1068-1070.

Grafen A, Hails R (2002) Modern statistics for the life science. New York: Oxford UP.

Granger CWJ (1980) Testing for causality: a personal viewpoint. J Econ Dyn Control 2:329-352.

Gruart A, Delgado-García JM (1994) Discharge of identified deep cerebellar nuclei neurons related to eye blinks in the alert cat. Neuroscience 61:665-681.

Gruart A, Blázquez P, Delgado-García JM (1995) Kinematics of spontaneous, reflex, and conditioned eyelid movements in the alert cat. J Neurophysiol 74:226-248.

Gruart A, Guillazo-Blanch G, Fernández-Mas R, Jiménez-Díaz L, DelgadoGarcía JM (2000) Cerebellar posterior interpositus nucleus as an enhancer of classically conditioned eyelid responses in alert cats. J Neurophysiol 84:2680-2690.

Gruart A, Streppel M, Guntinas-Lichius O, Angelov DN, Neiss WF, DelgadoGarcía JM (2003) Motoneuron adaptability to new motor tasks following two types of facial-facial anastomosis in cats. Brain 126:115-133.

Hair JF, Anderson RE, Tatham RL, Black WC (1998) Multivariate data analysis. Englewood Cliffs, NJ: Prentice Hall.

Holmes G (1939) The cerebellum of man. Brain 1:1-30.

Ito M (1984) The cerebellum and neural control. New York: Raven.

Jiménez-Díaz L, Navarro-López J de D, Gruart A, Delgado-García JM (2004) Role of cerebellar interpositus nucleus in the genesis and control of reflex and conditioned eyelid responses. J Neurosci 24:9138-9145.

Kitazawa S, Wolpert DM (2005) Rhythmicity, randomness and synchrony in climbing fiber signals. Trends Neurosci 28:611-619.

Koekkoek SK, Hulscher HC, Dortland BR, Hensbroek RA, Elgersma Y,
Ruigrok TJ, De Zeeuw CI (2003) Cerebellar LTD and learningdependent timing of conditioned eyelid responses. Science 301:1736-1739.

Krupa DJ, Thompson JK, Thompson RF (1993) Localization of a memory trace in the mammalian brain. Science 260:989-991.

Lang EJ, Sugihara I, Welsh JP, Llinas R (1999) Patterns of spontaneous Purkinje cell complex spike activity in the awake rat. J Neurosci 19:2728-2739.

Llinás R, Welsh JP (1993) On the cerebellum and motor learning. Curr Opin Neurobiol 3:958-965.

Ma Y, Hu H, Berrebi AS, Mathers PH, Agmon A (2006) Distinct subtypes of somatostatin-containing neocortical interneurons revealed in transgenic mice. J Neurosci 26:5069-5082.

Magarinos-Ascone C, Núñez A, Delgado-García JM (1999) Different discharge properties of rat facial nucleus motoneurons. Neuroscience 94:879-886.

Mauk MD (1997) Roles of cerebellar cortex and nuclei in motor learning: contradictions or clues? Neuron 18:343-346.

Medina JF, Christopher Repa J, Mauk MD, LeDoux JE (2002) Parallels between cerebellum- and amygdala-dependent conditioning. Nat Rev Neurosci 3:122-131.

Morcuende S, Delgado-García JM, Ugolini G (2002) Neuronal premotor networks involved in eyelid responses: retrograde transneuronal tracing with rabies virus from the orbicularis oculi muscle in the rat. J Neurosci 22:8808-8818.

Múnera A, Gruart A, Muñoz MD, Fernández-Mas R, Delgado-García JM (2001) Hippocampal pyramidal cell activity encodes conditioned stimulus predictive value during classical conditioning in alert cats. J Neurophysiol 86:2571-2582.

Seidler RD, Purushotham A, Kim SG, Ugurbil K, Willingham D, Ashe J (2002) Cerebellum activation associated with performance change but not motor learning. Science 296:2043-2046.

Shaw MD, Baker R (1985) Morphology of motoneurons in a mixed motor pool of the cat facial nucleus that innervate orbicularis oculis and quadratus labii superioris, stained intracellularly with horseradish peroxidase. Neuroscience 14:627-643.

Taganova AA, Silakov VL (1980) Use of a hierarchical cluster procedure to classify neuronal responses during conditioning. Neurosci Behav Physiol 10:429-431.

Thach WT, Goodkin HP, Keating JG (1992) The cerebellum and the adaptive coordination of movements. Annu Rev Neurosci 15:403-442.

Trigo JA, Gruart A, Delgado-García JM (1999) Discharge profiles of abducens, accessory abducens, and orbicularis oculi motoneurons during reflex and conditioned blinks in alert cats. J Neurophysiol 81:1666-1684.

Van Kan PLE, Houk JC, Gibson AR (1993) Output organization of intermediate cerebellum of the monkey. J Neurophysiol 69:57-73.

Welsh JP, Harvey JA (1991) Pavlovian conditioning in the rabbit during inactivation of the interpositus nucleus. J Physiol (Lond) 444:459-480.

Welsh JP, Llinás R (1997) Some organizing principles for the control of movement based on olivocerebellar physiology. Prog Brain Res 114:449-461.

Yeo CH, Hardiman MJ, Glickstein M (1985) Classical conditioning of the nictitating membrane response of the rabbit. I. Lesions of the cerebellar nuclei. Exp Brain Res 60:87-98. 